\title{
Contribution of some societal practices in rationalizing farmers' usage for irrigation water in some villages of Assiut governorate, Egypt
}

\author{
Fath El-Bab A. M. ${ }^{a}$, Abdel-hafez M. M. I. ${ }^{b^{*}}$ \\ ${ }^{a}$ Higher Institute for Cooperation and Agricultural Extension, Assuit, Egypt \\ ${ }^{b}$ Department of Agricultural Extension and Rural Sociology, Faculty of Agriculture, Al-Azhar University, Assuit, Egypt
}

\begin{abstract}
Research aimed to identify contribution of the studied some societal practices in total and detail in rationalization of the researched farmers 'usage of irrigation water, in some villages of Assiut governorate which are: prescriptive education, social control, organizational coordination, cooperation, farmers' participation, social adjustment, and social conflict. Too determining correlation between the studied independent variables and societal practices and the relative importance to contribution of this societal practices. Too determine the contribution ratios of independent variables with significant correlations, in explaining the total variation in respondents 'responses towards the total and overall contribution of the studied societal practices in rationalizing farmers' usage of irrigation water. Individuals of research sample were randomly selected from the registry of holdings for year 2019 in selected villages. To determine sample size of this research, $11.61 \%$ from total researchers was determined, which amounted to 2,670 farmers. Sample size reached 310 farmers. Who were distributed among the selected villages, according to their percentage in the overall research. Data of this research were collected through a personal interview with respondents from farmers using a questionnaire. This was prepared, and made sure of its validity to collect data, to achieve aims of this research. Time for data collection took from October to December of 2019. Data were analyzed using factor analysis and weighted average. To presentation of results using of frequencies and percentages. Most important results: $50.2 \%$ of respondents possess an area of less than an acre, and $50 \%$ of them consist of a once area, and $87.4 \%$ of them have the method of irrigating their lands by flooding. Most of the respondents fall into the high category due to total societal practices of Irrigation extension, social control, organizational coordination, and cooperation, and less than half of them fall into participation and social adjustment. While more than half of the respondents fall into the low category of societal practices related to social conflict. More than half of the respondents fell under intermediate category, at Percentage of $54.8 \%$, in their view to contribution of societal practices in their rationalization usage of irrigation water and $37.8 \%$ in high category. Most important societal practices that contribute to the rationalization of farmers 'usage of irrigation water were, in order: Irrigation extension, social control, organizational coordination, cooperation, farmers' participation, social adjustment, and social conflict. It was also evident that the independent variables with significant correlation were age, irrigation method used, and leadership, which contributed $22.4 \%$ in explaining overall variation of societal practices in rationalizing farmers' use of irrigation water.
\end{abstract}

Keywords: societal practices, rationalizing, irrigation water.

\footnotetext{
* Corresponding author: Abdel-hafez M. M. I.,
}

E-mail address: az2851374@gmail.com 


\title{
إسهام بعض الممارسات المجتمعية في ترشيد استخدام الزراع لمياه الري في بعض قرى محافظة أسيوطي بجمهورية مصر العربية
}

\author{
عبد الناصر محمد فتح الباب' ، محمد محمد إسماعيل عبد الحافظ' \\ 'المعهد العالي للتعاون و الإرشاد الزر اعي ، أسيوط ، جمهورية مصر العربية

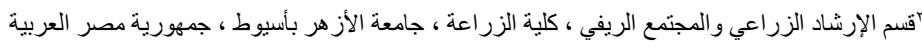

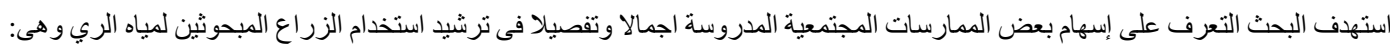

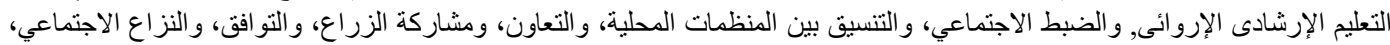

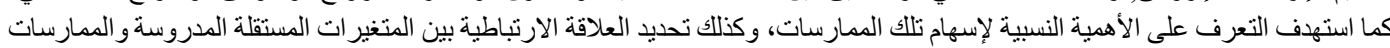

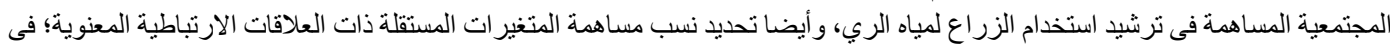

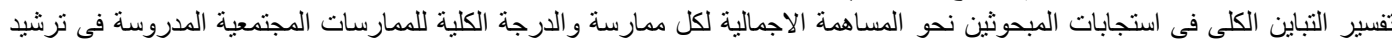

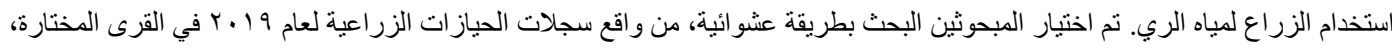

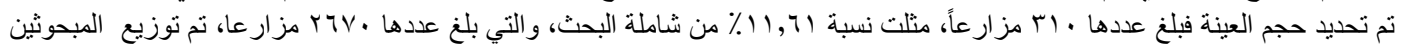

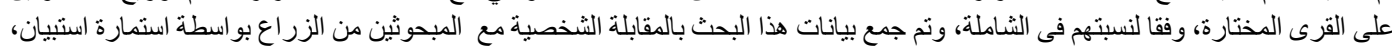

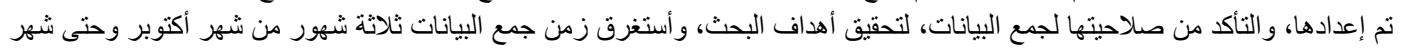

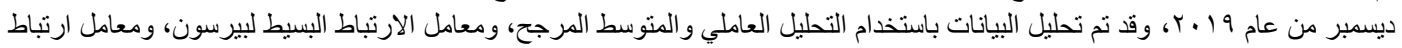

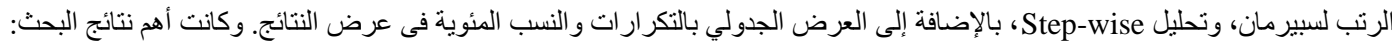

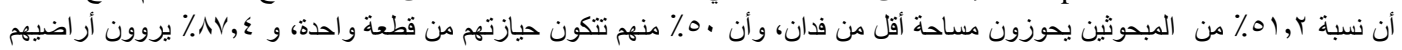

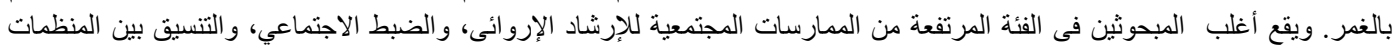

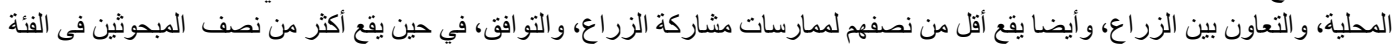

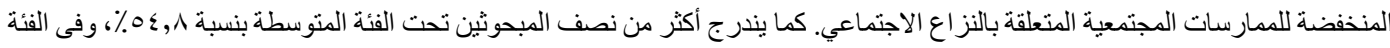

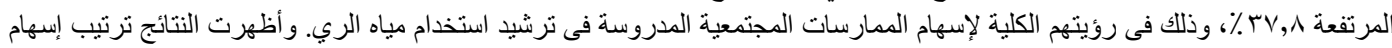

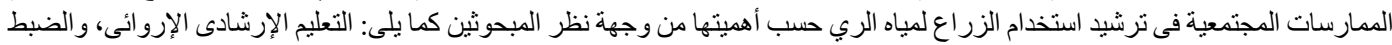

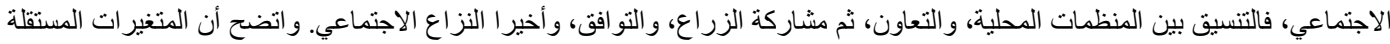

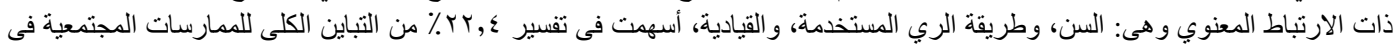
ترشيد استخدام الزراع لمياه الري.

كلمات دالة: الممارسات المجتمعية، ترشيد، مياه الري. 
ضــوط ثبات حصـة المياه وتعرضـها المحتمل للخفض، ووفقاً

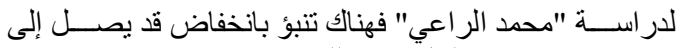

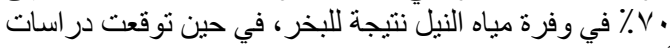

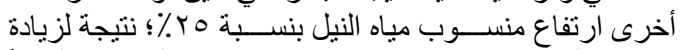

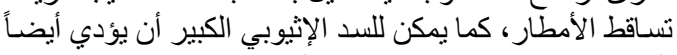

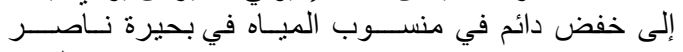
(https://ar.wikipedia.org/wiki, 2020)

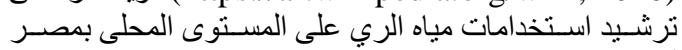

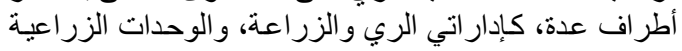

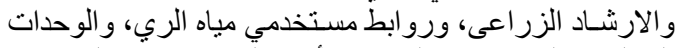

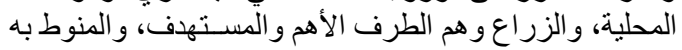

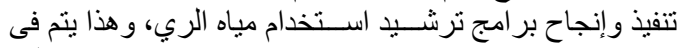

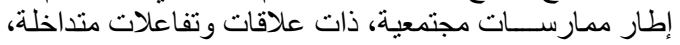

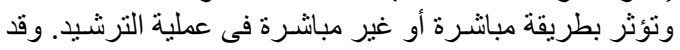

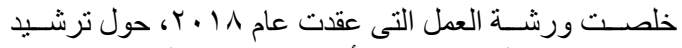

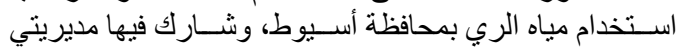

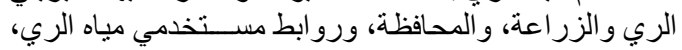

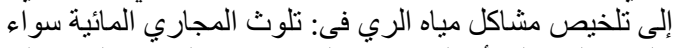

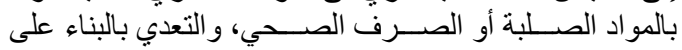

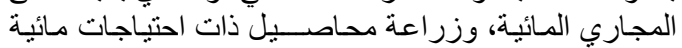

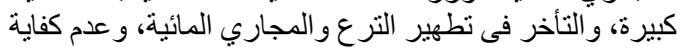

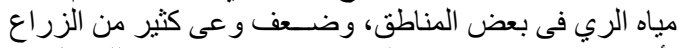

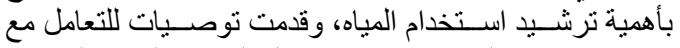

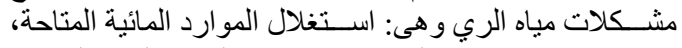

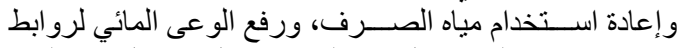

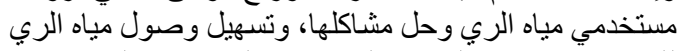

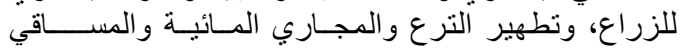

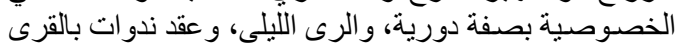

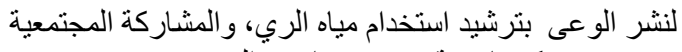
بـن ،(https://www.m.elwatannews.com, وتحدث الممارسات المجتمعية تغير ات وتفاعلات فى التعاملات

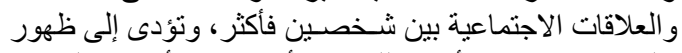

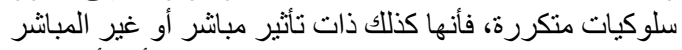

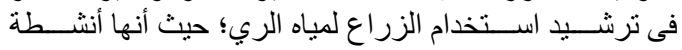

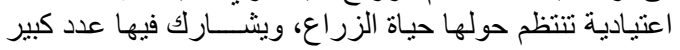

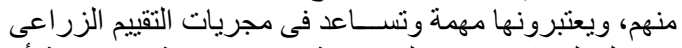

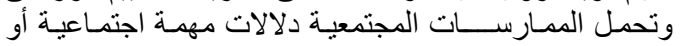

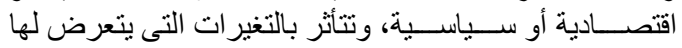

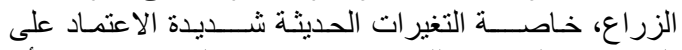

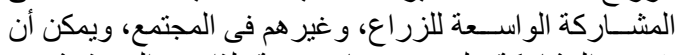

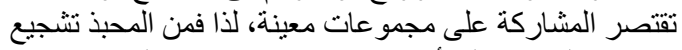

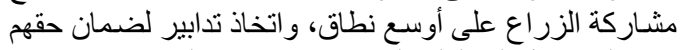

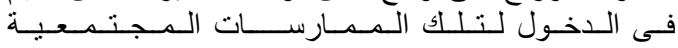
(https://www.ich.Unesco.org, 2020)

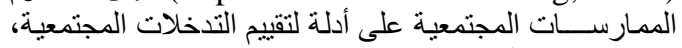

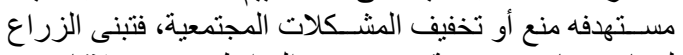

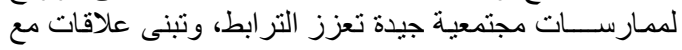

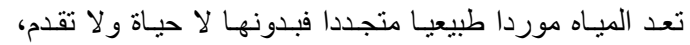

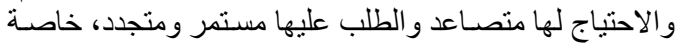

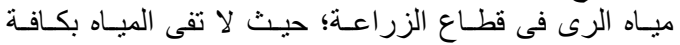

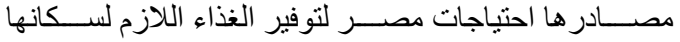

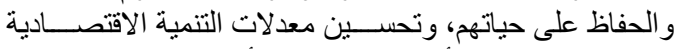

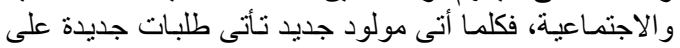

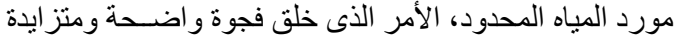

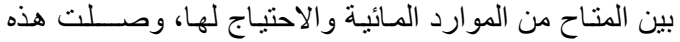

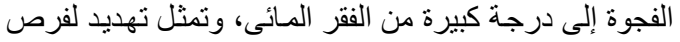

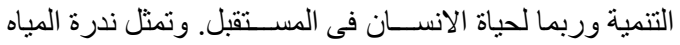

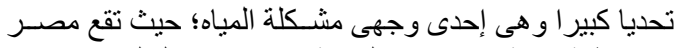

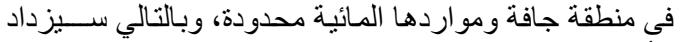

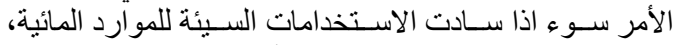

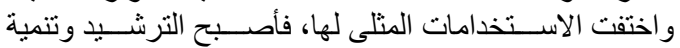

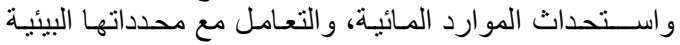

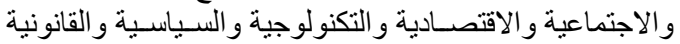

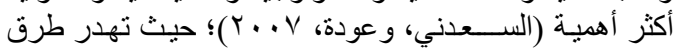

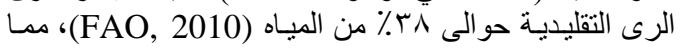

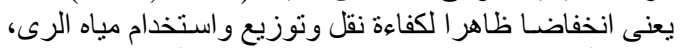

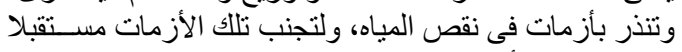

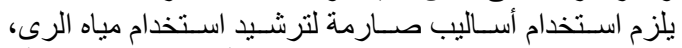

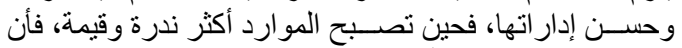

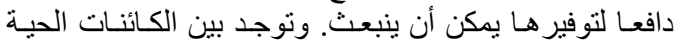

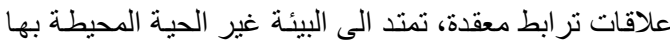

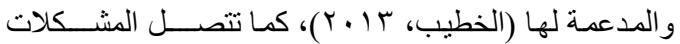

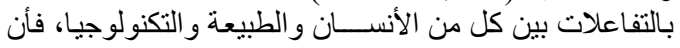

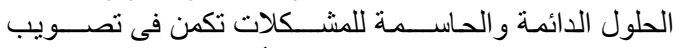

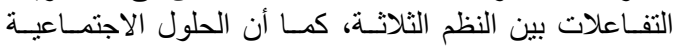

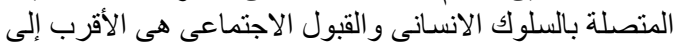

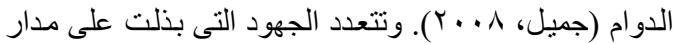

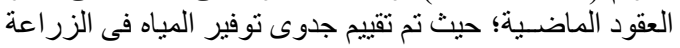

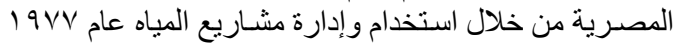

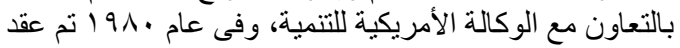

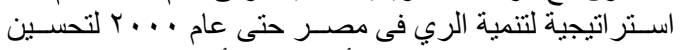

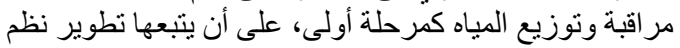

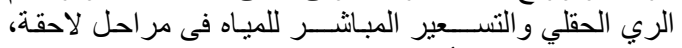

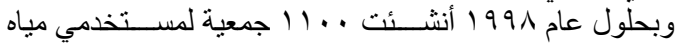

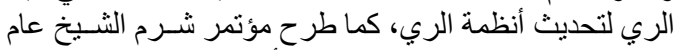

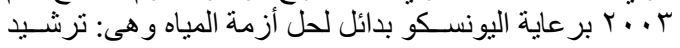

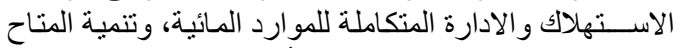

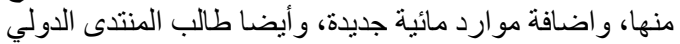

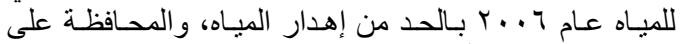

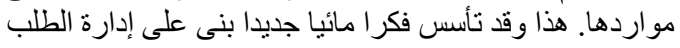

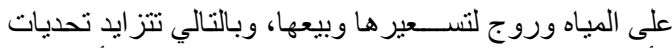

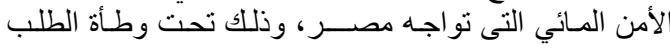

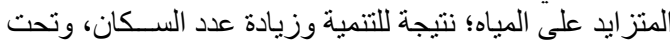


و الأعر اف ســيؤدى إلى نتائج مأســاوية (روبنس، وآخرون،

( $(r \cdot 1)$

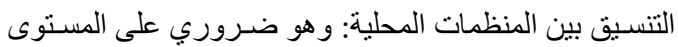

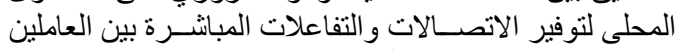

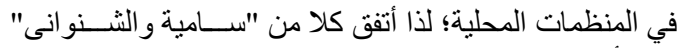

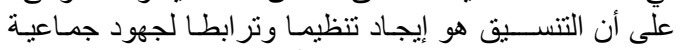

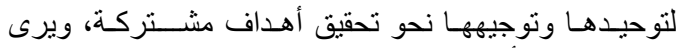

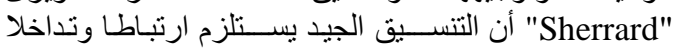

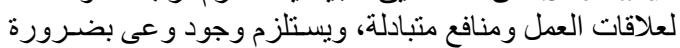

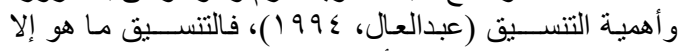

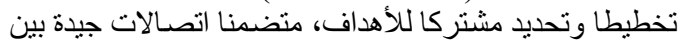
المنظمات، ومرونة فى تنفيذ الأنشطة والمهام المهام.

التعاون: يقول "روبرت اكسلر وروس هاموند" أن الفرد يختار

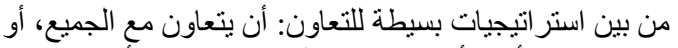

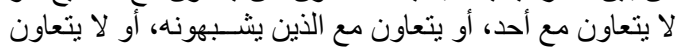

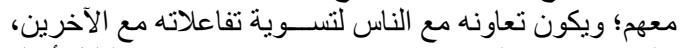

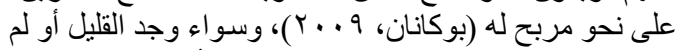

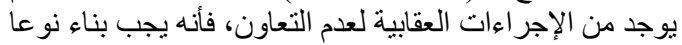

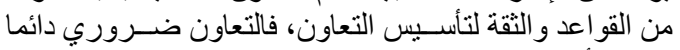

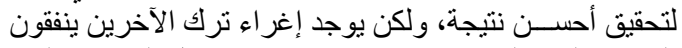

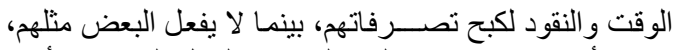

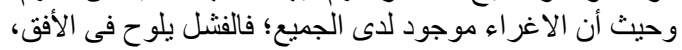

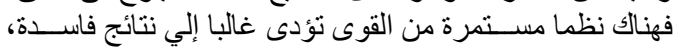

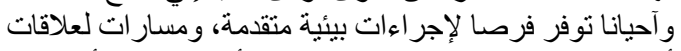

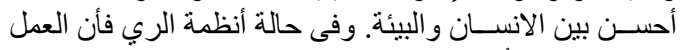

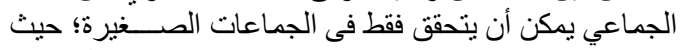

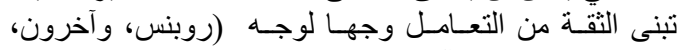

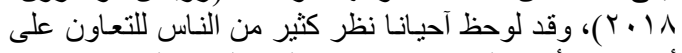

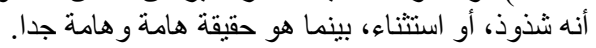

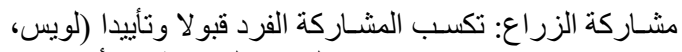

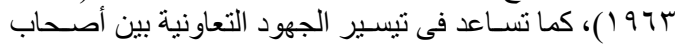

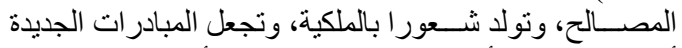

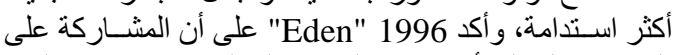

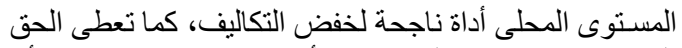

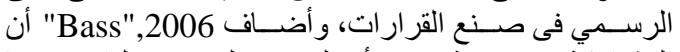

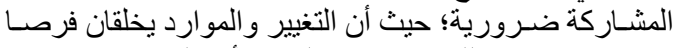

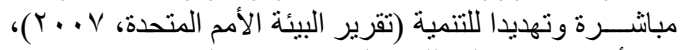

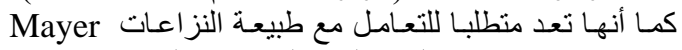

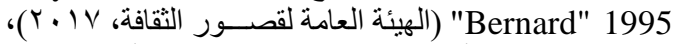

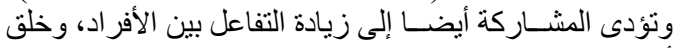

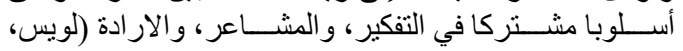

. (1974

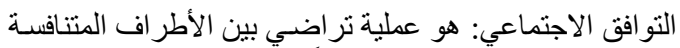

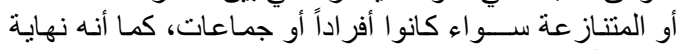

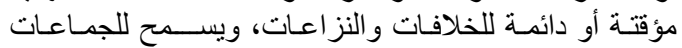

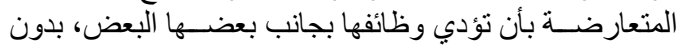

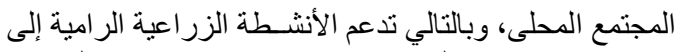

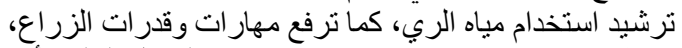

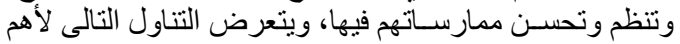

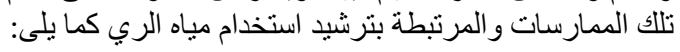

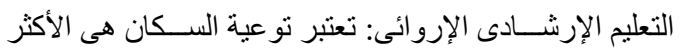

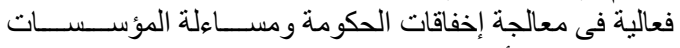

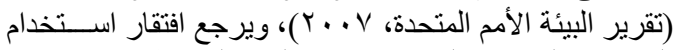

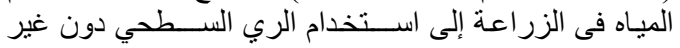

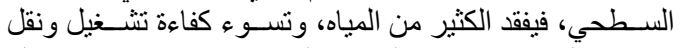

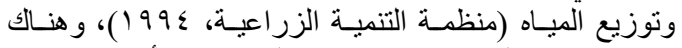

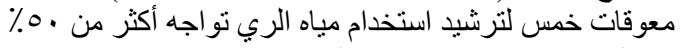

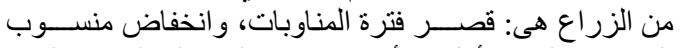

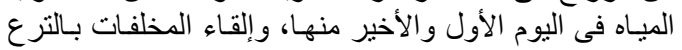

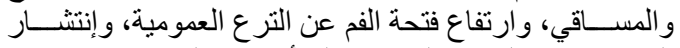

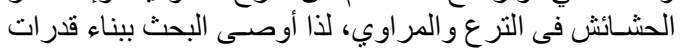

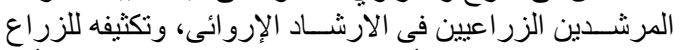

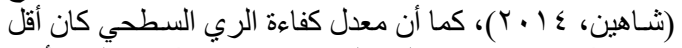

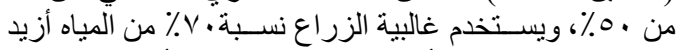

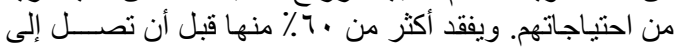

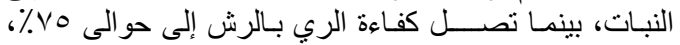

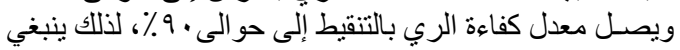

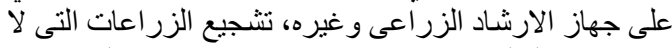

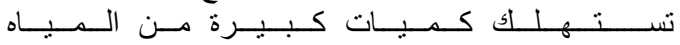

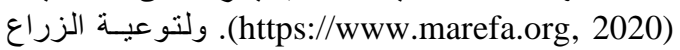

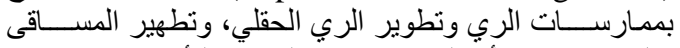

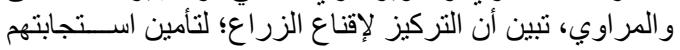

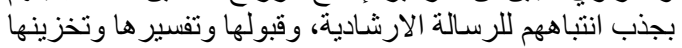

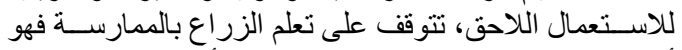

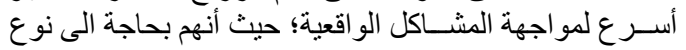

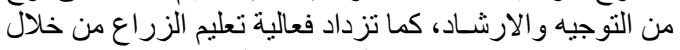

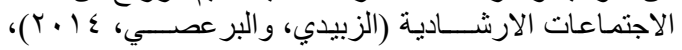

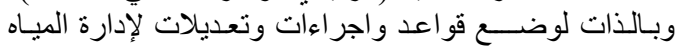

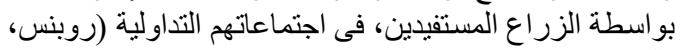

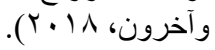

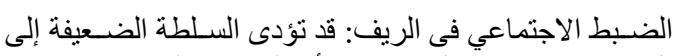

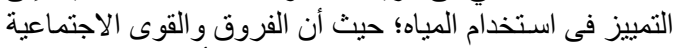

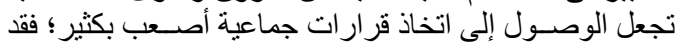

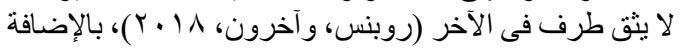

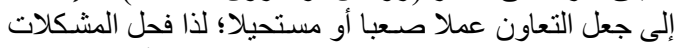

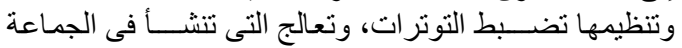

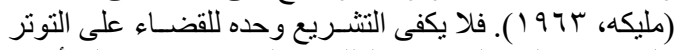

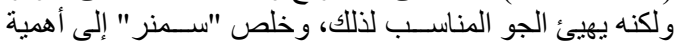

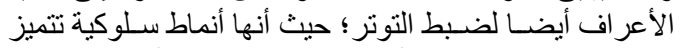

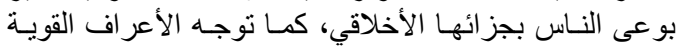

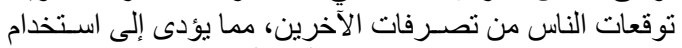

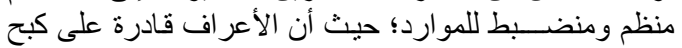
السلوك، و الوصول إلى نتيجة تعاونية، فالغياب الكامل للتشريع 


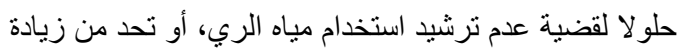

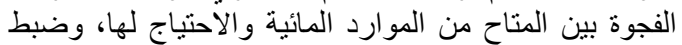

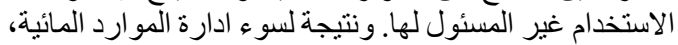

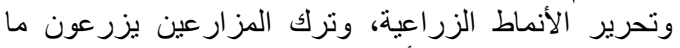

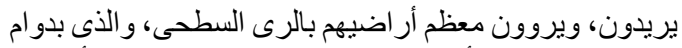

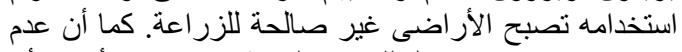

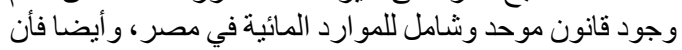

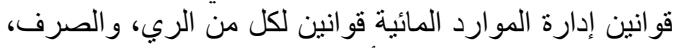

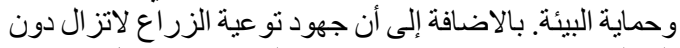

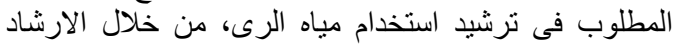

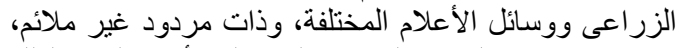

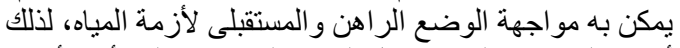

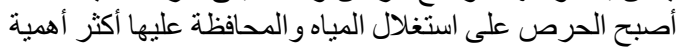

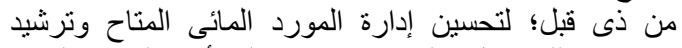

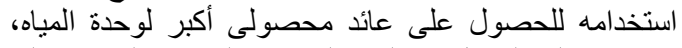

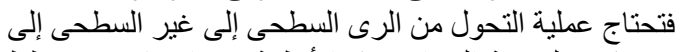

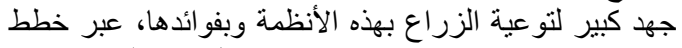

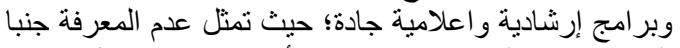

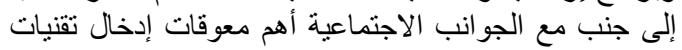

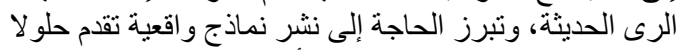

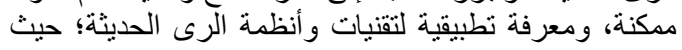

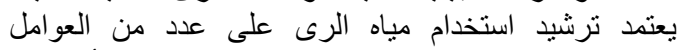

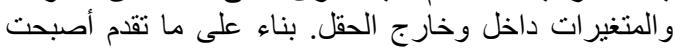

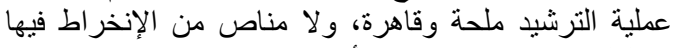

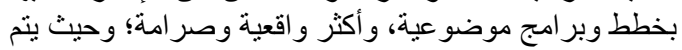

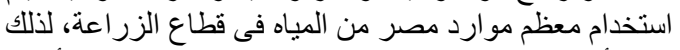

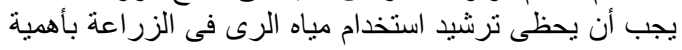

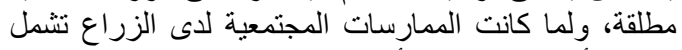

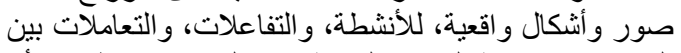

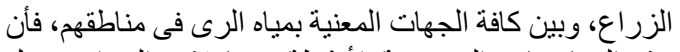

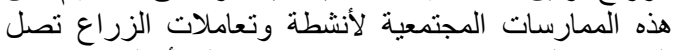

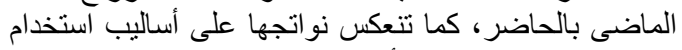

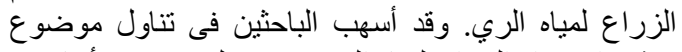

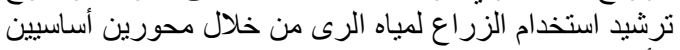

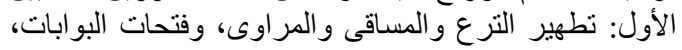

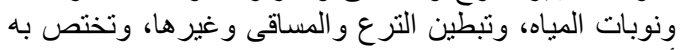

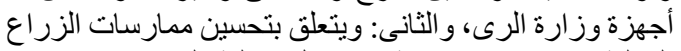

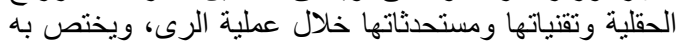

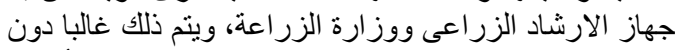

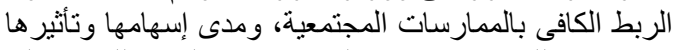

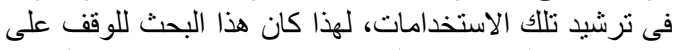

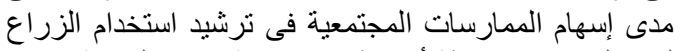
لمياه الرى فى محافظة أسيوط بجمهورية المصنية مصر العربية.

\section{التعاريف الاجرائية}

1- الممارسات المجتمعية: ويقصد بها الأنشطة الاعتيادية

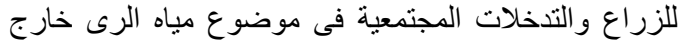

أي عداء واضح، فالتو افق لا يزيل أسباب الخلاف نهائياً، ولكنه

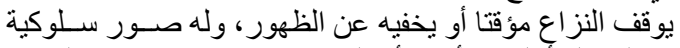

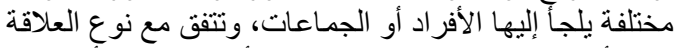

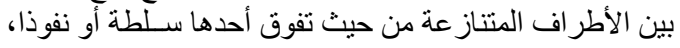

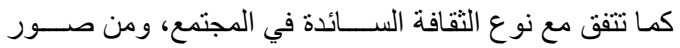

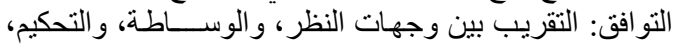

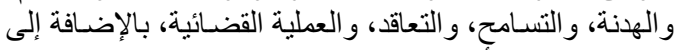

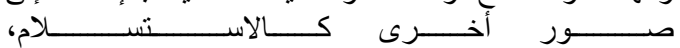
و التبرير (https://fac.ksu.edu.sa/sites, 2020).

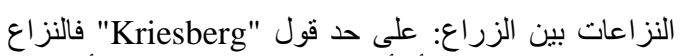

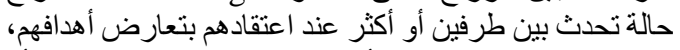

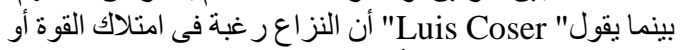

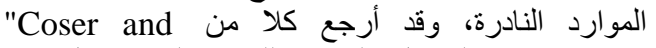
كriesberg"

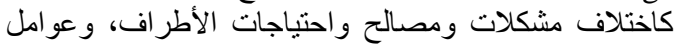

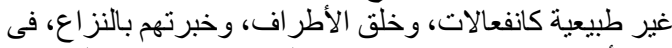

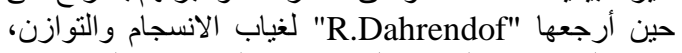

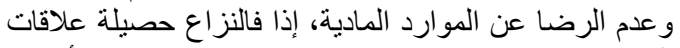

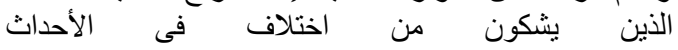
،(https://www.ar.wikinbooks.orglwiki, 2011)

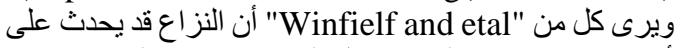

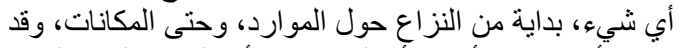
يحدث أيضاهي بين الأفر اد، أو الجماعات، أو كليهما (الهيئة العامة

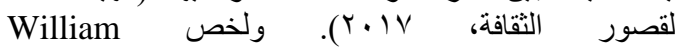

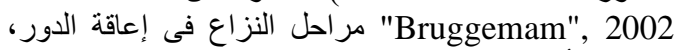

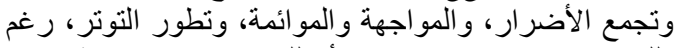

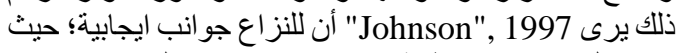

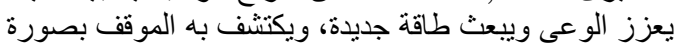

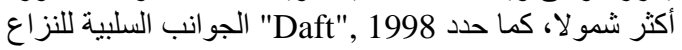

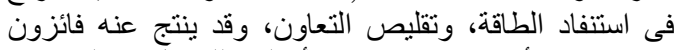

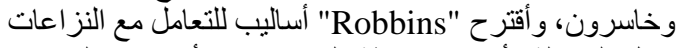
كحل المشكلة، أو إيجاد نقطة التقاء كبيرة، أو زيادة المباد الموارد،

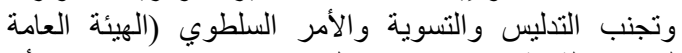

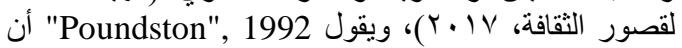

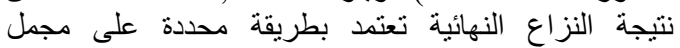

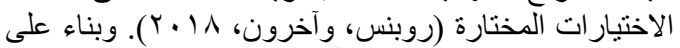

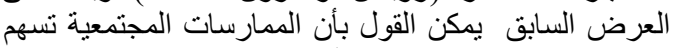

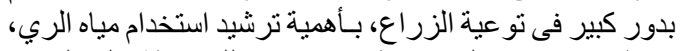

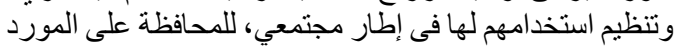

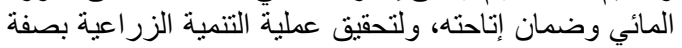
خاصةّ، و التنمية الثاملة المستدامة بصفة علية عامة.

\section{مشكثة البحث}

تتصاعد وتيرة الانشغال و التوتر الظاهر لدى الساسة والباحثين

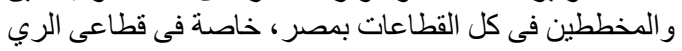

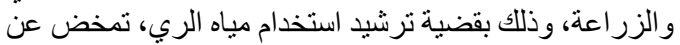
ذللك عقد المؤتمر ات، ووضع سياسات وخططا ليتم تنفيذها، لتقدم 


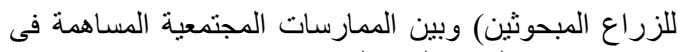

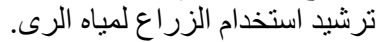

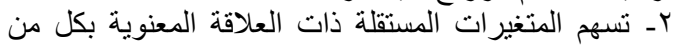

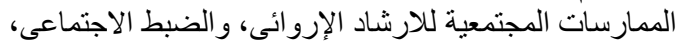

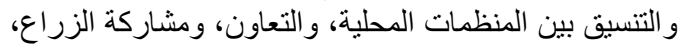

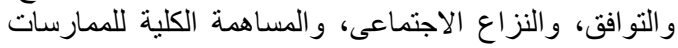

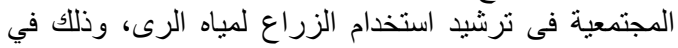

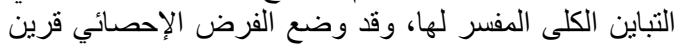

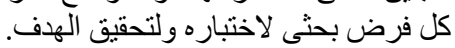

\section{الطريقة البحثية}

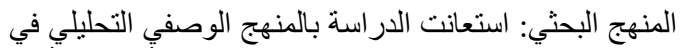

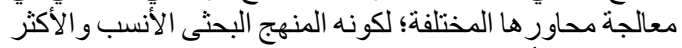

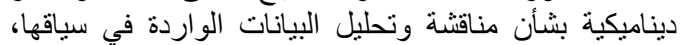
وبقصد تحقيق أهدافها.

منطقة البحث: تم إجراء هذا البحث في أرئ أربع قرى بمحافظة

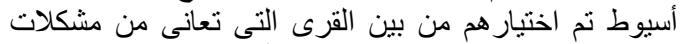

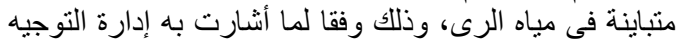

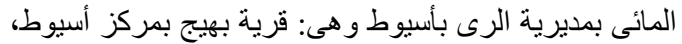

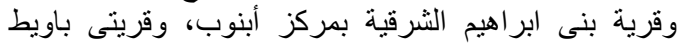

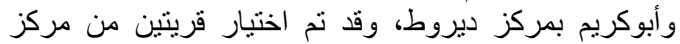

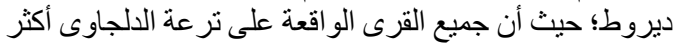

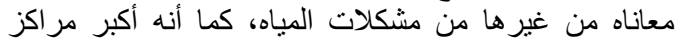

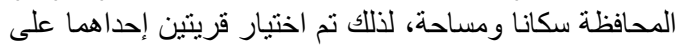

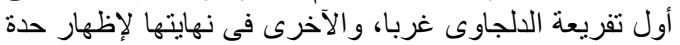
المشكلة وتباينها.

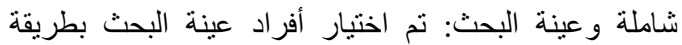

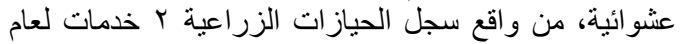

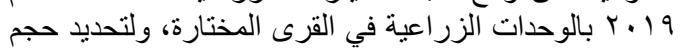

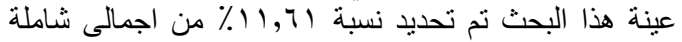

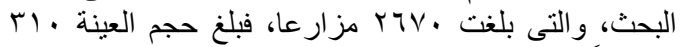

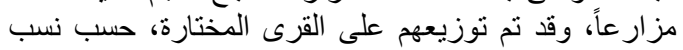

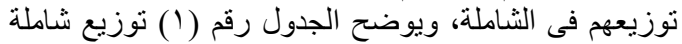
و عينة البحث.

أدوات البحث: بداية تم تصميم استمارة استبيان للممارسات

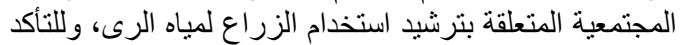

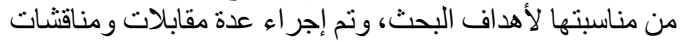

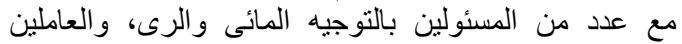

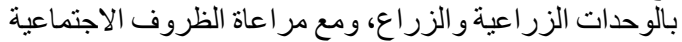

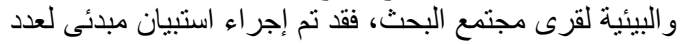

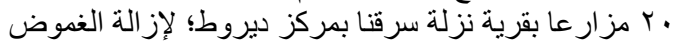

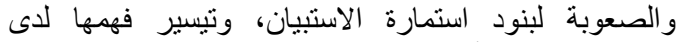

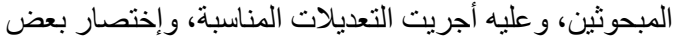

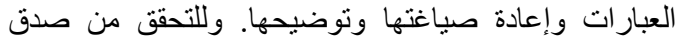

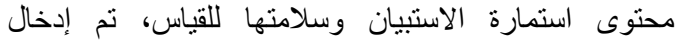

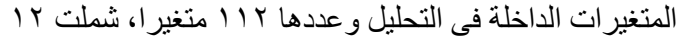

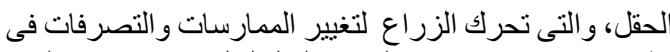

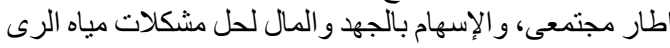
وضبط استخدامه.

rـ الترشيد: وهو تنظيم أنشطة الزراع المتعلقة باستخدام مياه

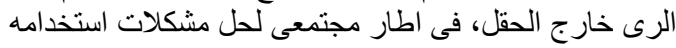
وتيسير اتاحه مياه الرى في الطي

أهمية البحث

ترجع أهمية هذا البحث تطبيقيا فقد تسهم نتائجه بأن يكون مدخلا

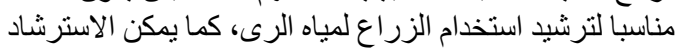

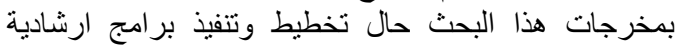

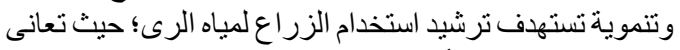

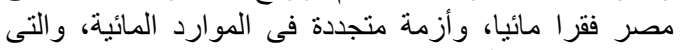

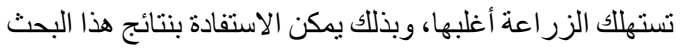

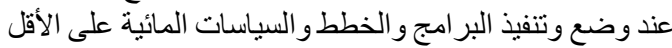

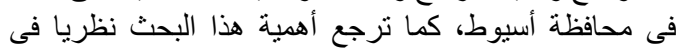

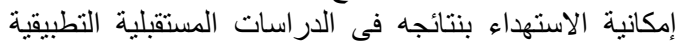

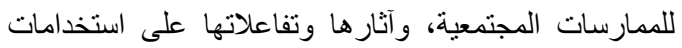

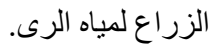

\section{أهداف البحث}

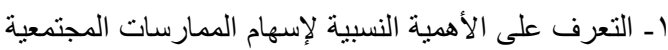

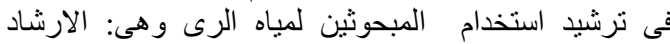

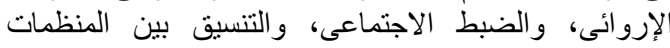

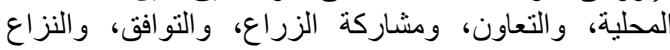

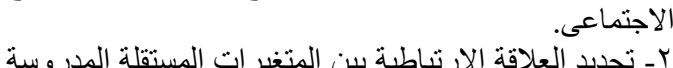

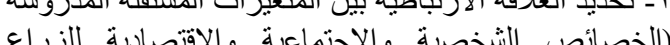

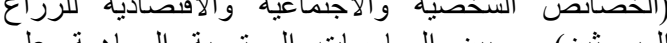
المبحوثين) وبين الممارسات المجتمعية المساهمة على للى لاعلى

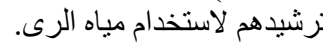

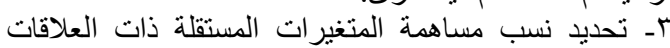

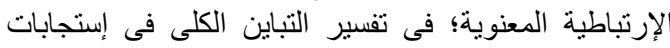

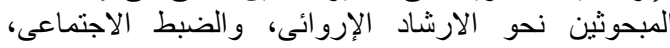

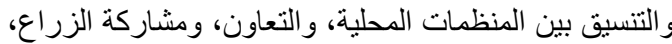

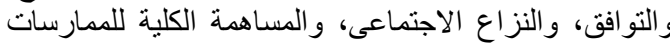

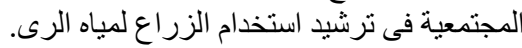

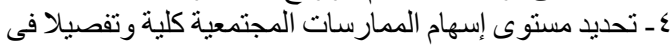

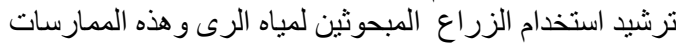

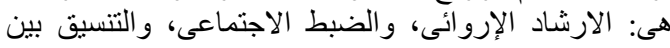

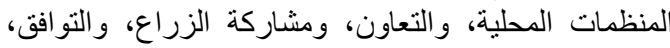

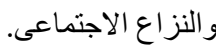

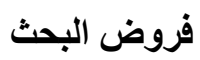

اـ توجد علاقة ارتباطية معنوية بين المتغيرات المستقلة الدروسة (الخصائص الثخصية والاجتماعية والاقتصادية 
والنزاع الاجتماعي بين الزراع، مستبعدا باقي المتغيرات و والممارسات المجتمعية.

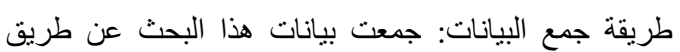

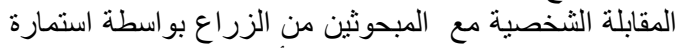

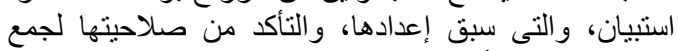

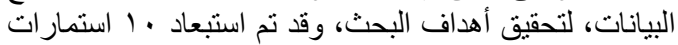

لعدم استيفاء بياناتها.

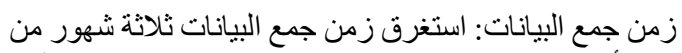

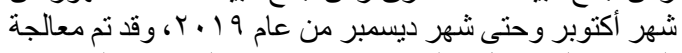

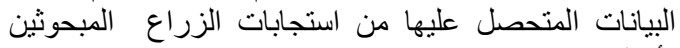
لأسئلة استمارة الاستبيان كميا.

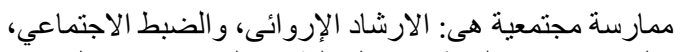

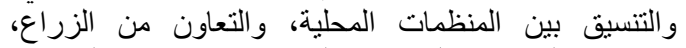

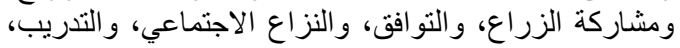

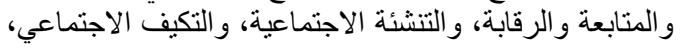

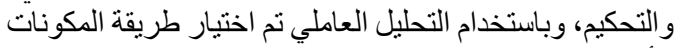

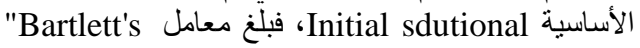
بلج

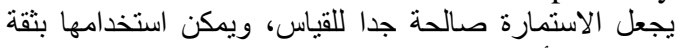

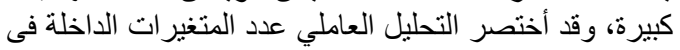

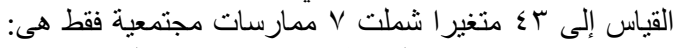

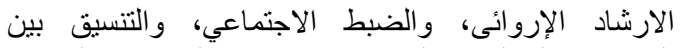
المنظمات المحلية، والتعاون، ومشاركة الزئي، الزراع، والتوافق،

جدول (1) ) توزيع شاملة و عينة البحث بالقرى المختارة بمحافظة أسيوط.

\begin{tabular}{|c|c|c|c|}
\hline عبنة البحث & عدد الحائزين & القرى & المركز \\
\hline$r \wedge$ & rT人 & بنى ابر اهيم الثرقية & أبنوب \\
\hline VV & 771 & بهيج & أسيوط \\
\hline 1.1 & $\lambda V_{1}$ & باويط & \multirow[t]{2}{*}{ ديروط } \\
\hline $1 \cdot \varepsilon$ & $9 \ldots$ & أبوكريم & \\
\hline ऑ. & TTV. & \multicolumn{2}{|c|}{ المجموع } \\
\hline
\end{tabular}

المصدر : سجلات r خدمات للحياز ات الزر اعية لعام 9 1 ب بالوحدات الزر اعية بالقرى المختارة للبحث.

هـ طريقة الرى المستخدمة: ويقصد بها الطريقة التى يستخدمها

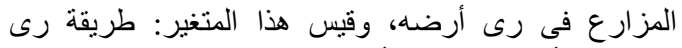

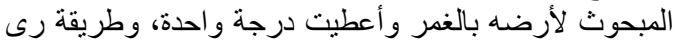

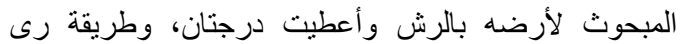

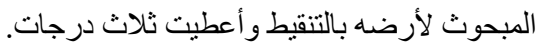

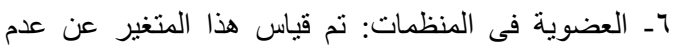

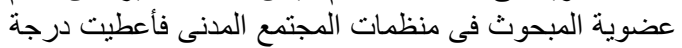

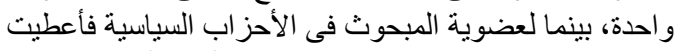

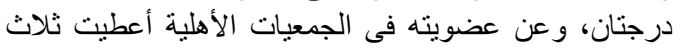

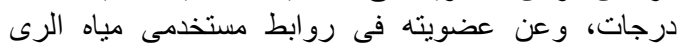
فأعطيت أربعة درجات.

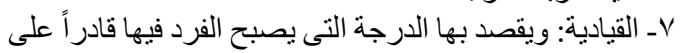

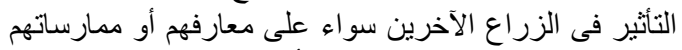

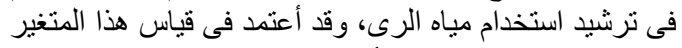

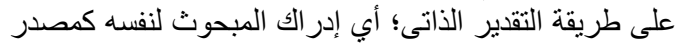

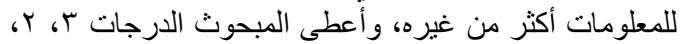
ا للاستجابات دائما، و آحيانا، ونادر أعلى العى الترتيب.

$$
\text { ثانباً: المتغير التابع }
$$

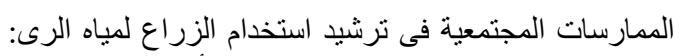

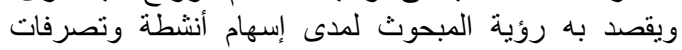

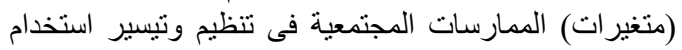

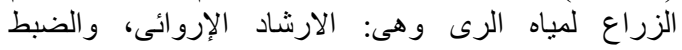

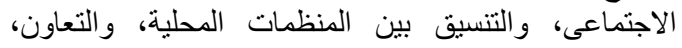
ومشاركة الزراع، والتو افق، والنزاع الاجتماعى، وذللك فى ولئ

\section{القياس الرقمى للبيانات}

أو لا: المتغير ات المستقلة

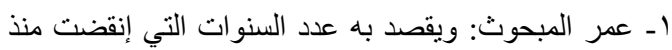

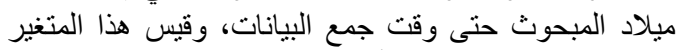

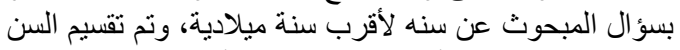

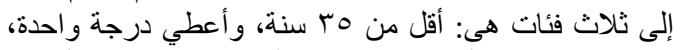

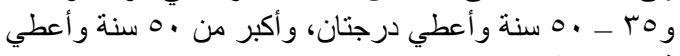

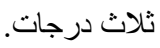
r- مستوى التعليم: تم قياس هذا المتغير بتقسيمه إلى مسنويات

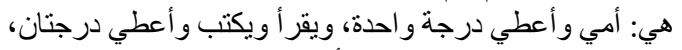

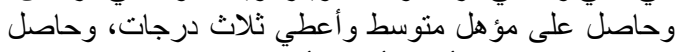

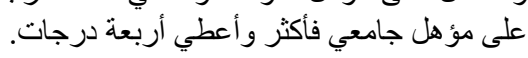

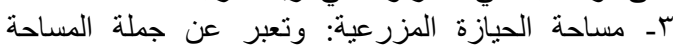

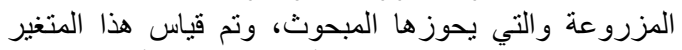

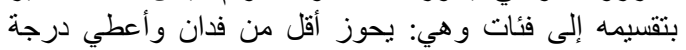

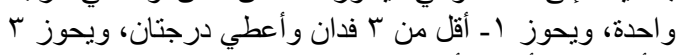

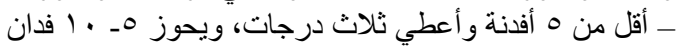

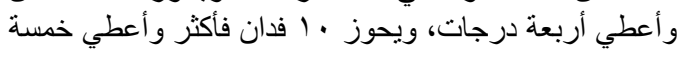

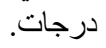

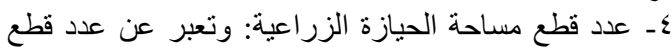

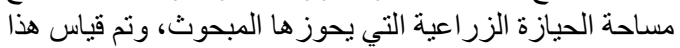

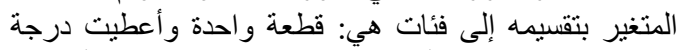

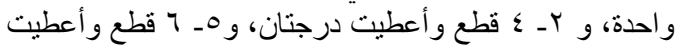
ثلاث درجات، و أكثر من 1 قطع و أعطيت أربعة درجات 


\section{ثانيا: الأهمية النسبية لإسهام الممارسات المجتمعية فى ترشيد استخدام الزراع لمياه الري لإسيات}

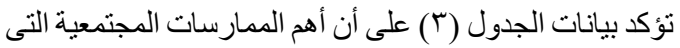

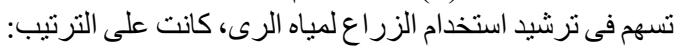

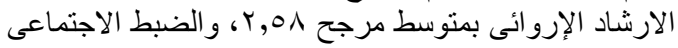

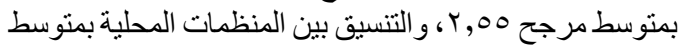

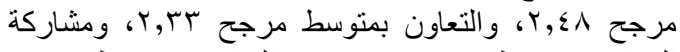

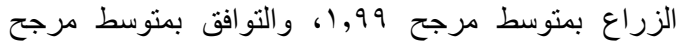

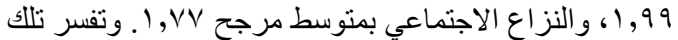

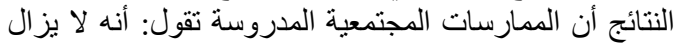

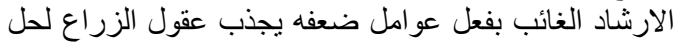

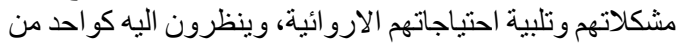

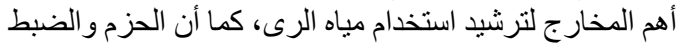

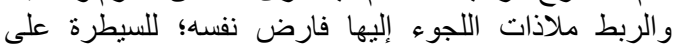

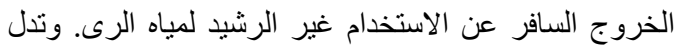

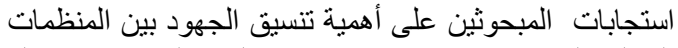

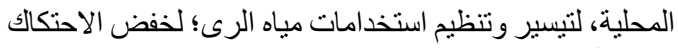

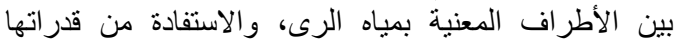

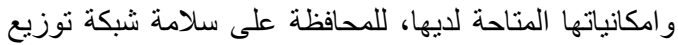

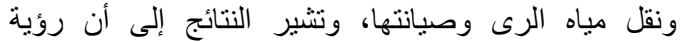

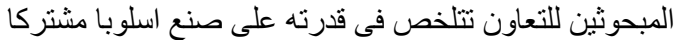

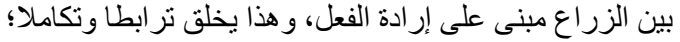

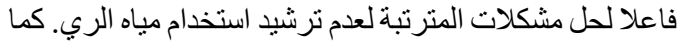

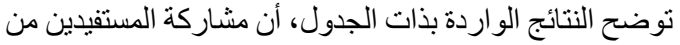

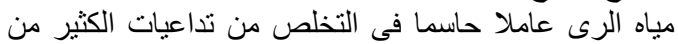

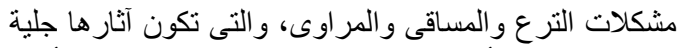

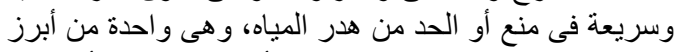

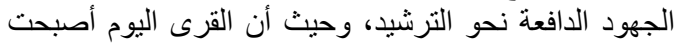

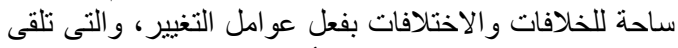

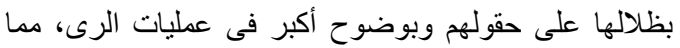

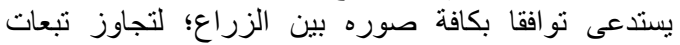

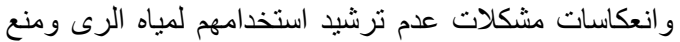

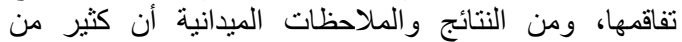

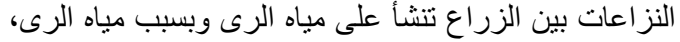

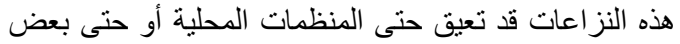

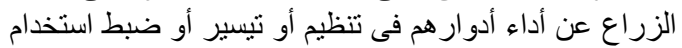

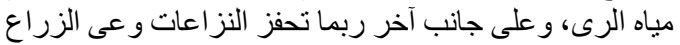

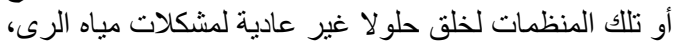

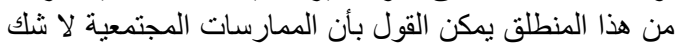

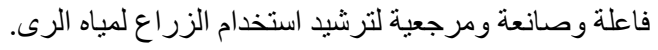

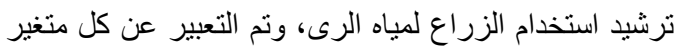

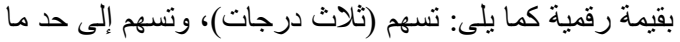

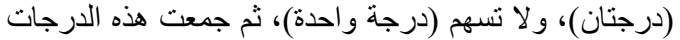

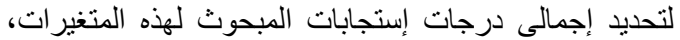

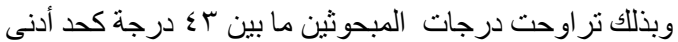

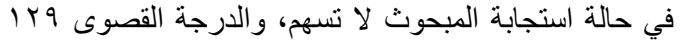

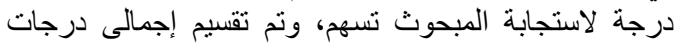

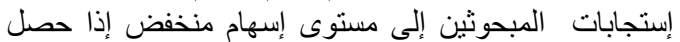

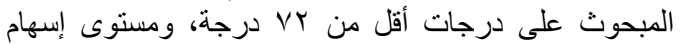

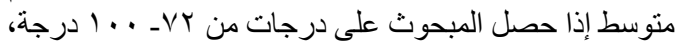

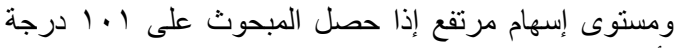
فأكثر.

\section{التحليل الإحصائي}

تم الاعتماد على الحاسب الآلي في الإدخال والتوصيف الإنيف

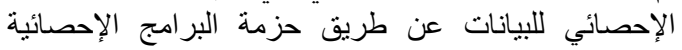

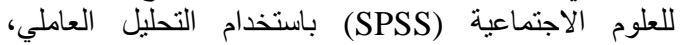

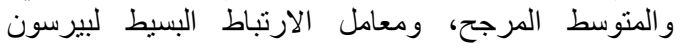

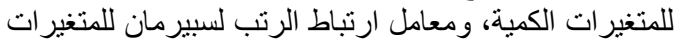

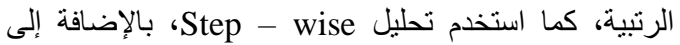

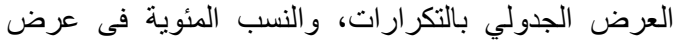

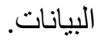

\section{النتائج ومناقشتهها}

\section{أولا: خصائص المبحوثين الثخصية والاجتماعية والاقتصادية}

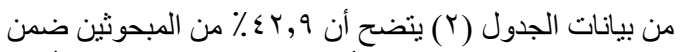

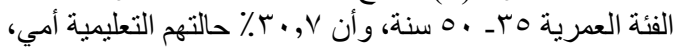

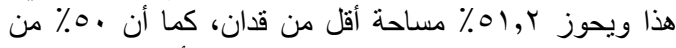

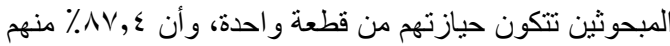

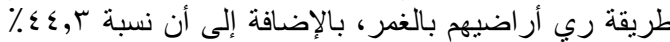

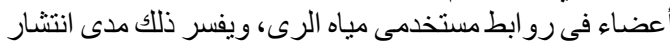

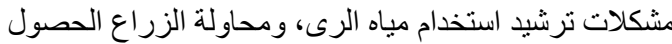

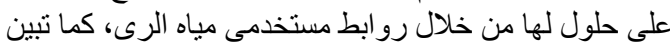

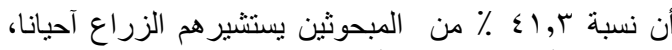

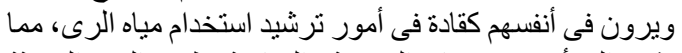

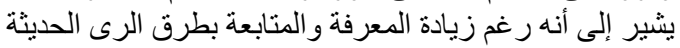
لكن ييدو أن تحديات عدم تبنيها أكبر من ذلك. 
Fath El-Bab and Abdel-hafez / Archives of Agriculture Sciences Journal 3(3) 391-411, 2020.

\begin{tabular}{|c|c|c|c|}
\hline$\%$ & عدد & المكونات & خصائص المبحوثين \\
\hline $\mathrm{IV}, \xi$ & $0 \leqslant$ & أقل من هب سنة & \multirow{3}{*}{ السن ل } \\
\hline$\varepsilon r, q$ & (Tr & 0.- 0. 0. سنة & \\
\hline$r q, v$ & TKT & أكثر من •0 سنة & \\
\hline$r \cdot, v$ & 90 & أمى & \multirow{4}{*}{ الحالة التعليمية } \\
\hline$r q, r$ & 91 & يقر أويكتب & \\
\hline$T V, \varepsilon$ & 10 & حاصل على مؤ هل منوسط & \\
\hline $1 Y, 7$ & rq & حاصل على مؤهل عالى & \\
\hline $01, r$ & 109 & أقل من فدان & \multirow{5}{*}{ مساحة الحيازة الزراعية } \\
\hline 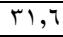 & 91 & أقل من ؟ فدان & \\
\hline$I r, r$ & rA & أقل من ه فدان & \\
\hline$r, q$ & IT & •ـ · 1 فدان & \\
\hline 1 & $r$ & أكثر من · 1 فدان & \\
\hline 0. & 100 & قطعة و احدة & \multirow{4}{*}{ عدد قطع مساحة الحيازة الزر اعية } \\
\hline$\varepsilon r, r$ & $1 \pi \varepsilon$ & r- ع قطع & \\
\hline$r, 0$ & 11 & 0ـ7 قطع & \\
\hline$r, r$ & 1. & أكثر من 7 قطع & \\
\hline$\Lambda \mathrm{V}, \Sigma$ & rVI & بالغمر & \multirow{3}{*}{ طريقة الرى المستخدمة } \\
\hline $0, r$ & 17 & بالرش & \\
\hline$V, \varepsilon$ & tr & بالثتقيط & \\
\hline$\varepsilon \varepsilon, r$ & $1 \pi V$ & رو ابط مستخدمى مياه الرى & \multirow{4}{*}{ العضوية فى المنظمات } \\
\hline., 7 & $r$ & الجمعيات الاهلية & \\
\hline$\cdot, r$ & 1 & احز اب سياسية & \\
\hline $0 \leqslant, \wedge$ & $1 V \cdot$ & ليس لدية عضوبة & \\
\hline$r, 9$ & 99 & دائما & \multirow{3}{*}{ القيادية } \\
\hline$\sum 1, r$ & TrA & آحيانا & \\
\hline$r \uparrow, \Lambda$ & $\Delta r$ & نادرا & \\
\hline
\end{tabular}

جدول (r)): الأهمية النسبية لإسهام الممارسات المجتمعية فى نرشيد استخدام الزر اع لمياه الرىى.

\begin{tabular}{|c|c|c|}
\hline المتوسط المرجح & الأهمية النسبية لإسهام الممارسات المجتمعية المدروسة فى ترشيد استخدام مياه الري & الرتبة \\
\hline$r, 0 \Lambda$ & التعليم الارشادى الإرو ائى & 1 \\
\hline$r, 00$ & الضبط الاجتماعي لدى الزر اع & tr \\
\hline$T, \sum \wedge$ & التنسيق بين المنظمات المحلية & $r$ \\
\hline T,rT & التعاون & $\varepsilon$ \\
\hline 1,99 & مشاركة الزراع & 0 \\
\hline 1,99 & التو افق بين الزراع & 7 \\
\hline $1, \mathrm{VV}$ & النزاع الاجتماعى بين الزراع & $\mathrm{v}$ \\
\hline$r, r \cdot$ & المنوسط المرجح الإجمالي المئ & \\
\hline
\end{tabular}

$$
\text { مصدر البيانات: استمارة الاستبيان ، ن= •l" لم. }
$$

وتم تحديد معنوية علاقتها الارتباطية بمعامل ارتباط الرتب لسبيرمان.

ا ـ العلاقة الارتباطية بين المتغيرات المستقلة الكمية وينين

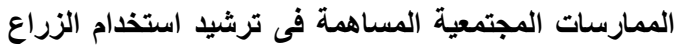
لمياه الري

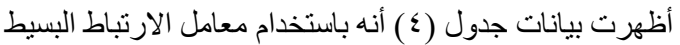

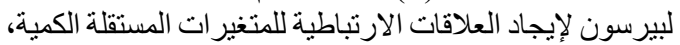

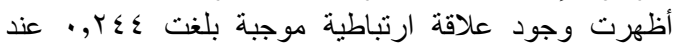

ثالثا: العلاقات الارتباطية بين المتغيرات المستقلة (خصائص

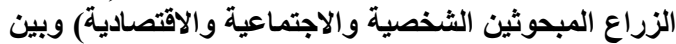

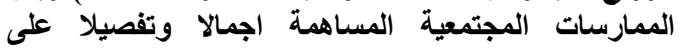
ترشيد هم لاستخدام مياه الري

بداية تم تقسيم المتغيرات المستقلة إلى متغيرات كمية وهى:

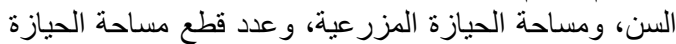

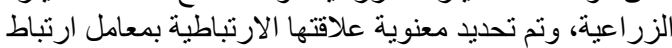

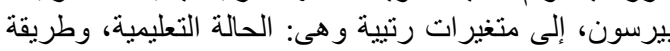

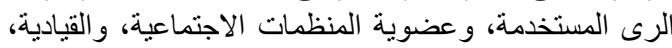




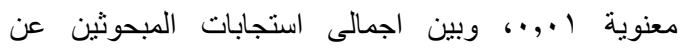

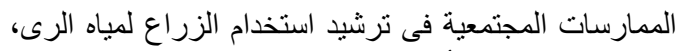

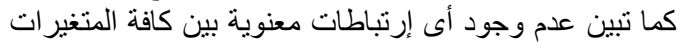

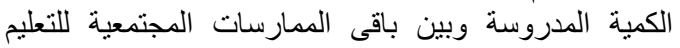

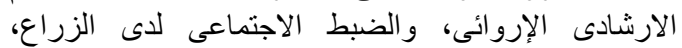

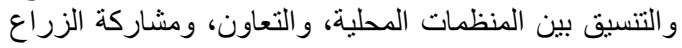
لترشيد استخدام مياه الرى.

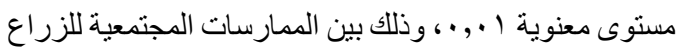

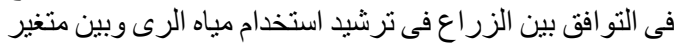

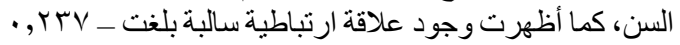

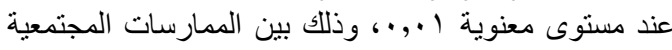

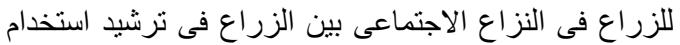

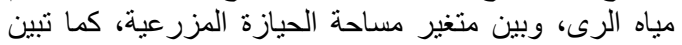

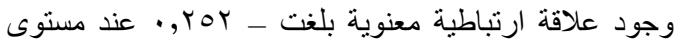

\begin{tabular}{|c|c|c|c|}
\hline عدد قطع مساحة الحيازة الزر اعية & مساحة الحيازة المزر عية & 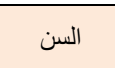 & الممارسات المجتمعية المتغير ات المستقلة \\
\hline$\cdot, \cdot, \varepsilon \leqslant-$ & $\cdot, \cdot Y_{7}$ &.,$+Y_{4}$ & التعليم الإرشادى الإروائى \\
\hline., $.09-$ &.,$+Y_{T}$ &., $1 \cdot r_{-}$ & الضبط الاجتماعي لدى الزراع \\
\hline$\cdot, \cdot, \wedge_{-}$ & $\cdot, \ldots r$ & $\cdot, \times 7_{-}$ & التنسيق بين المنظمات المحلية \\
\hline., $.7 r_{-}$ &.,$\cdot r V$ & $\cdot, \cdot, \vee \cdot-$ & التعاون \\
\hline.,$\cdot \vee 0_{-}$ & $\cdot, 1 \cdot r$ & $\cdot, 1 \cdots$ & مشاركة الزراع \\
\hline$\cdot, . \times 4_{-}$ &., .10 & $* * ., Y \leq \varepsilon$ & التو افق بين الزراع \\
\hline$\cdot,, 1 \cdot \varepsilon_{-}$ & $* * ., Y M V_{-}$ &.,$+11-$ & النزاع الاجتماعى بين الزراع \\
\hline$\cdot, \cdot, V V_{-}$ &.,$\cdot$ rY - & *., YOY - & اجمالى الممارسات المجتمعية \\
\hline
\end{tabular}

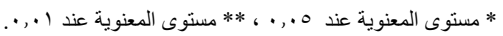

الممارسات المجتمعية لمشاركة الزراع لترشيد استخدام مياه

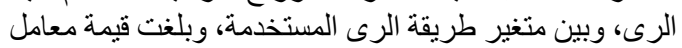

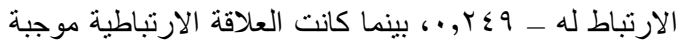

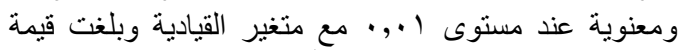

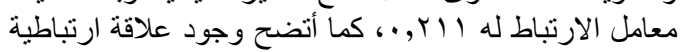

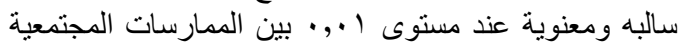

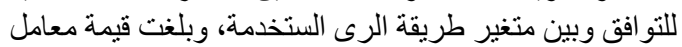

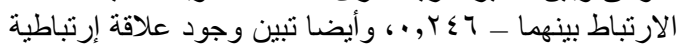

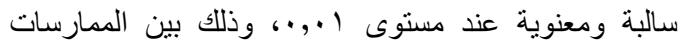

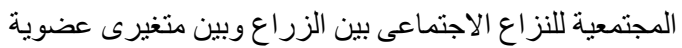

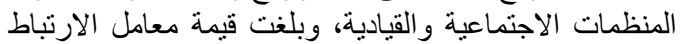

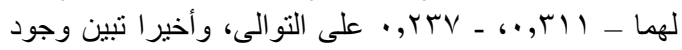

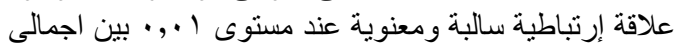

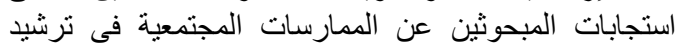

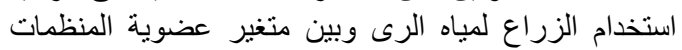

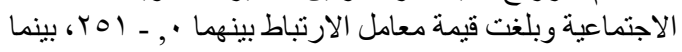

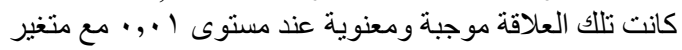

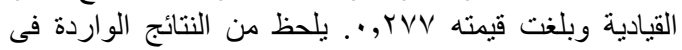

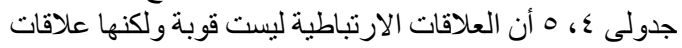

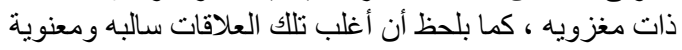

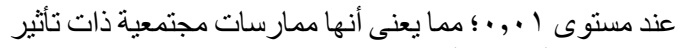

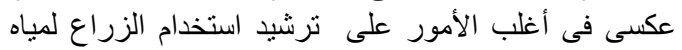
الرى، ويلزم تصحيح وتعديل مسار ها. r. العلاقة الارتباطية بين المتغيرات المستقلة الرتبية وبين الممارسات المجتمعية المساهمة في ترشيد الميديد استخدام الزراع لمياه الري

أظهرت بيانات جدول (0) أنه باستخدام معامل إرتباط سبير مان

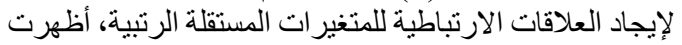

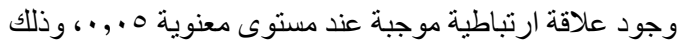

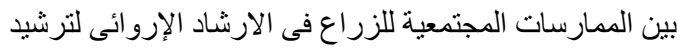

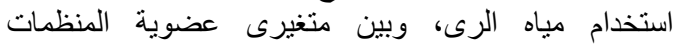

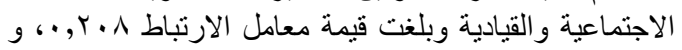

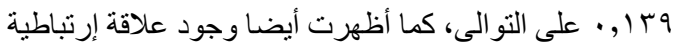

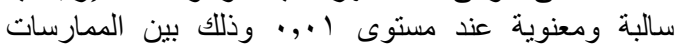

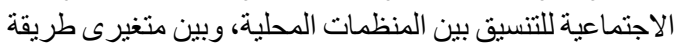

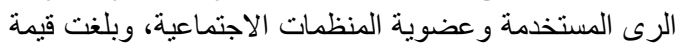

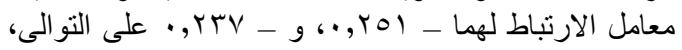

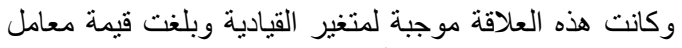

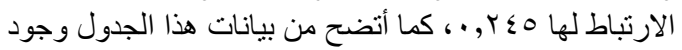

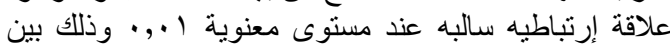

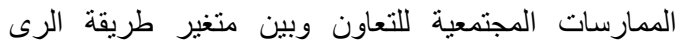

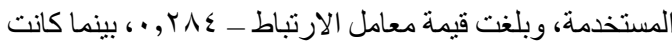

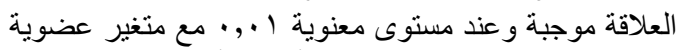

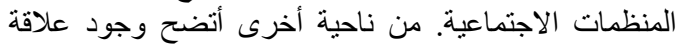

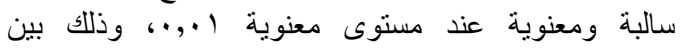


Fath El-Bab and Abdel-hafez / Archives of Agriculture Sciences Journal 3(3) 391-411, 2020.

\begin{tabular}{|c|c|c|c|c|}
\hline القيادية & عضوية المنظمات الاجتماعية & طريقة الرى المستخدمة & الحالة التعليمية & الممارسات المجتمعية المتغير ات المستقلة \\
\hline$*, 11 r 9$ & $* \cdot, r \cdot \wedge$ &.,$\cdot V T_{-}$ &., .91 & التعليم الارشادى الإرو ائى \\
\hline$\cdot, \cdot . \leqslant 0$ & ., & $\cdot, \cdot r \leq-$ & $\cdot, \cdot r \leq-$ & الضبط الاجتماعى لدى الزراع \\
\hline$* *_{,}, r \leq 0$ & $\cdot, I_{1} Y_{-}$ & $* *,, Y T V_{-}$ & $* *, Y 01-$ & التنسيق بين المنظمات المحلية \\
\hline$\cdot, \ldots 1$ & $*,, I \wedge r$ & $* *,, Y \wedge \varepsilon-$ & $\cdot,+\vee 1$ & التعاون \\
\hline$* ., r \backslash 1$ &.,., $9_{-}$ & $* * ., r \leq 9-$ & $\cdot, \cdot, \leqslant Y_{-}$ & مشاركة الزراع \\
\hline$\cdot, 1 \cdot \varepsilon$ &., .9 & $* * ., Y \leq 7-$ & $\cdot, \cdot \wedge \varepsilon-$ & التو افق بين الزراع \\
\hline$* *, r Y T V_{-}$ & $* *, \Gamma ! 1-$ & ., &.,$\cdot r T$ & النزاع الاجتماعى بين الزراع \\
\hline$* *, r V V$ & $\cdot,+1 \cdot$ & $* * ., Y 01-$ & $\cdot, .11$ & اجمالى الممارسات المجتمعية \\
\hline
\end{tabular}

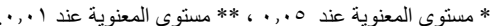

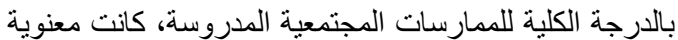

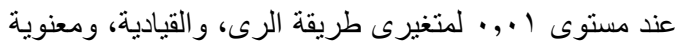

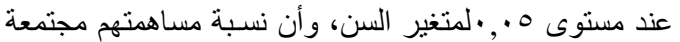

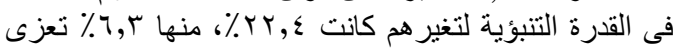

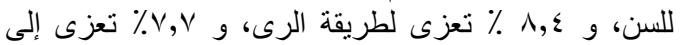

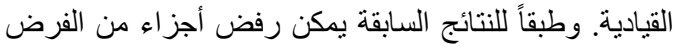

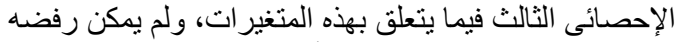

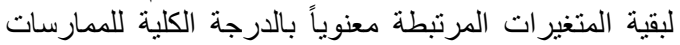

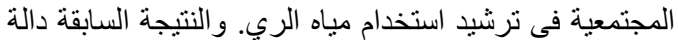

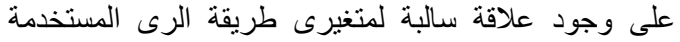

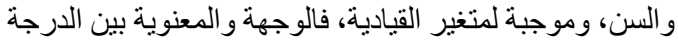

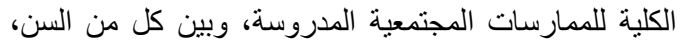

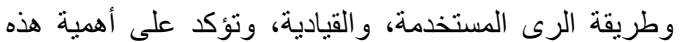

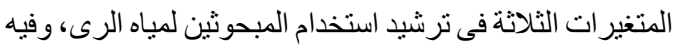

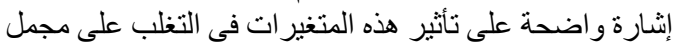

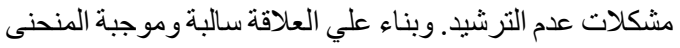

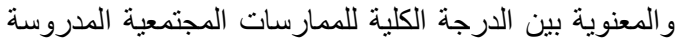

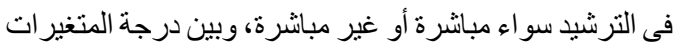

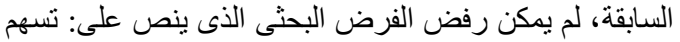

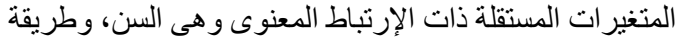

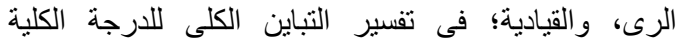

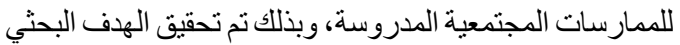

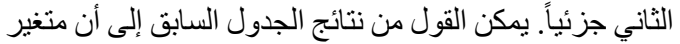

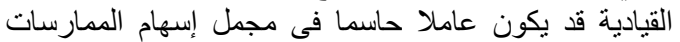

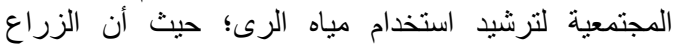

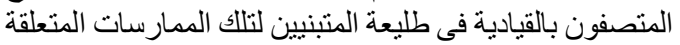

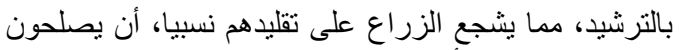

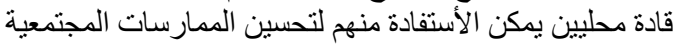

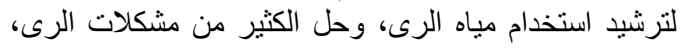

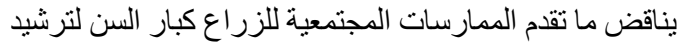

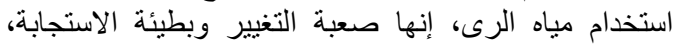

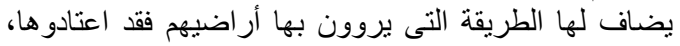

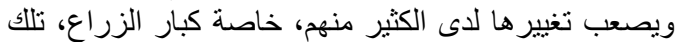
النتائج تقول بأن تغيير تلك الممارسات المجتمعية لبيت بالأمر لئر
رابعا: علاقة إستجابات المبحوثين للممارسات المجتمعية المدروسة بالمتغيرات المستقلة

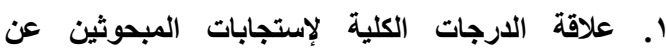 الممارسات المجتمعية بالمتغيرات المستقلة المدروسة المبنة}

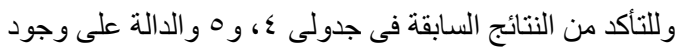

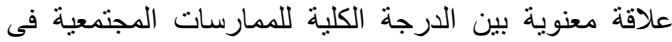

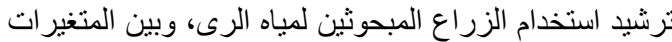

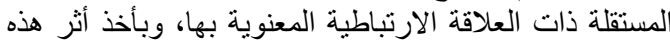

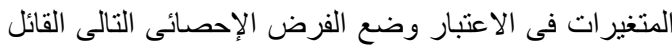

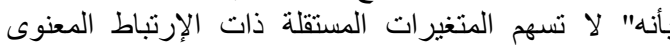

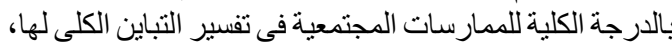

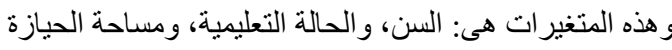

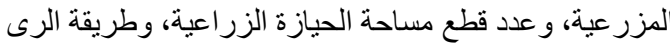
الاستخدمة، و وعضوية المنظمات الاجتماعية، و والقيادية.

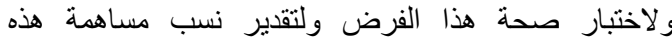

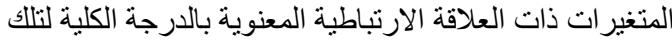

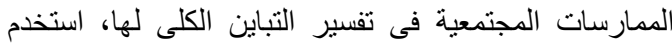

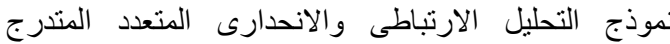

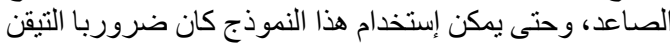

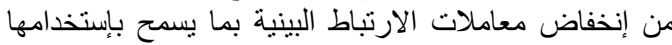

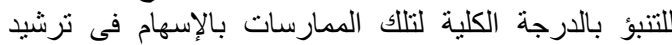

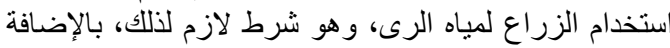

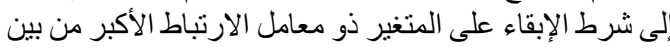

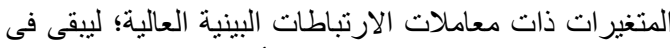

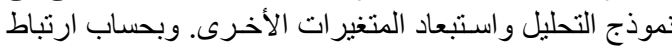

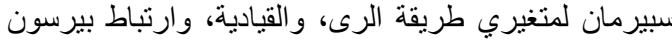

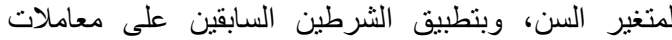

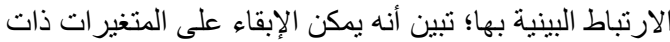

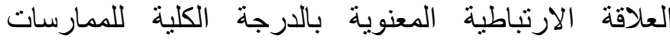

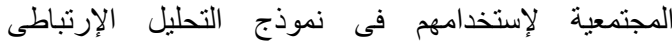

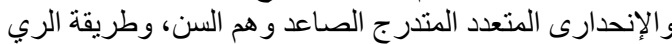

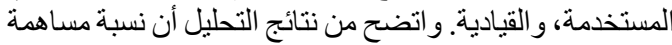
المتغيرات الثناثة السابقة فى تفسير التباين الكلى المعنى أنسية 


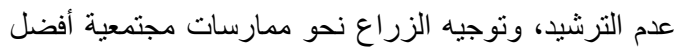

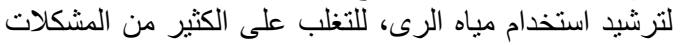
القائمة لعدم الترشيد (جدول آ).

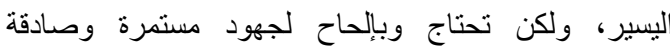
ومخططة؛ لتحسين الممارسات المجتمعية للزراع العياع لترشيد

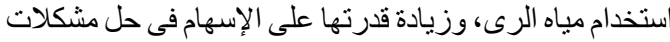

جدول (†): نتائج التحليل الإرتباطي و الإنحداري المتعدد المتندرج الصــــاعد للعلاقة بين الدرجات الكلية لإســتجابات المبحوثين عن الممارسات المجتمعية وبين المتغير ات الاجتماعية و الاقتصادية المدروسية.

\begin{tabular}{|c|c|c|c|c|c|}
\hline قالميمة فية & معامل الانحدار & \% للتباين المفسر & \% التر اكمية للتباين المفسر & معامل الارتباط & في التغلير المستقل الداخل \\
\hline$* V, .11$ &., $1 \vee 9$ &., $.7 r$ &., $.7 r$ &.,$+\wedge 1$ & النسن الن \\
\hline$* * \backslash r, \wedge \cdot \wedge$ & $\cdot, 110$ & $\cdot, \cdot \wedge \varepsilon$ & $\cdot, 1 \leqslant V$ & $\cdot, \cdot \wedge \varepsilon$ & طريقة الري \\
\hline$* * 1,9,9,9$ & $\cdot, 1 \wedge \wedge$ &.,$\cdot \mathrm{VV}$ & $\cdot, Y Y \leq$ &., 111 & القيادية \\
\hline
\end{tabular}

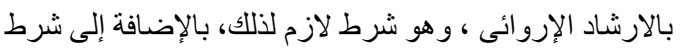

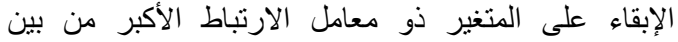
المتغير ات ذات معاملات الارتباطات البينية العالية؛ لييقى في الإكى

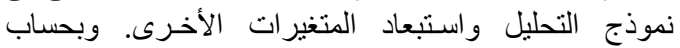

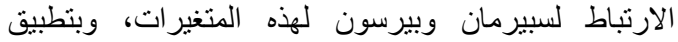

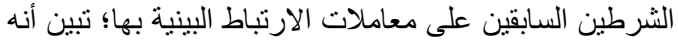

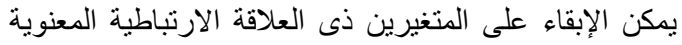

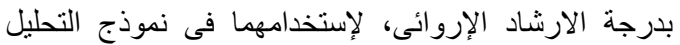

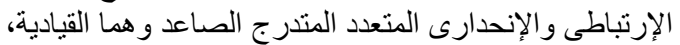

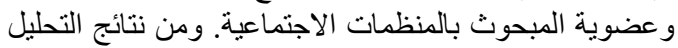

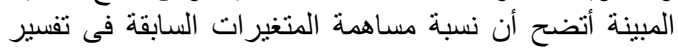

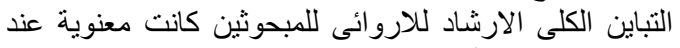

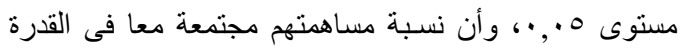

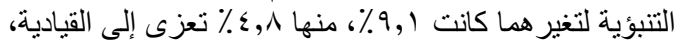

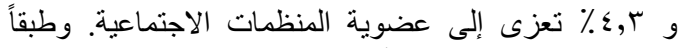

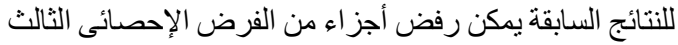

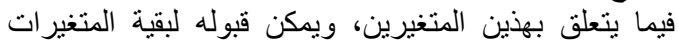

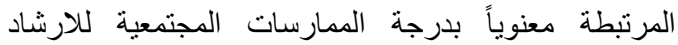

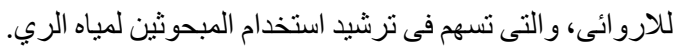

\section{r. علاقة درجة استجابات المبحوثين عن الممارسات}

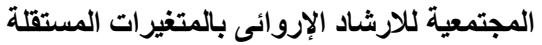

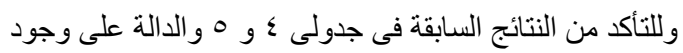

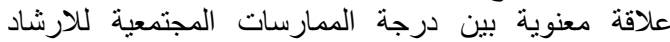

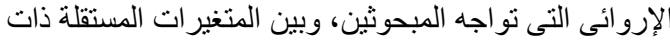

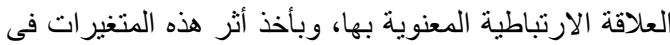

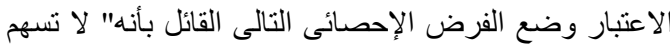

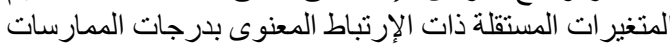

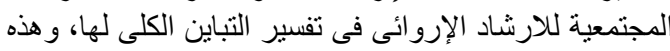

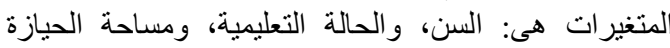

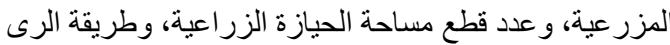

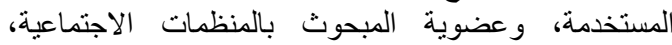

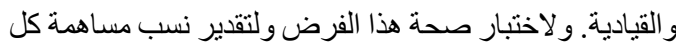

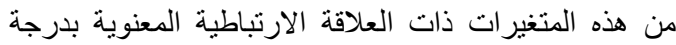

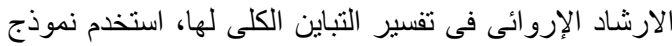

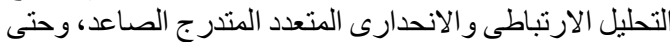

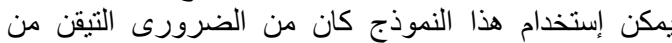

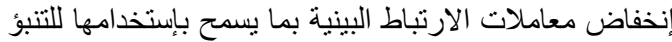

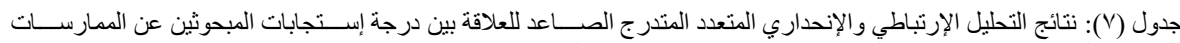

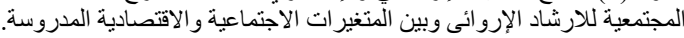

\begin{tabular}{|c|c|c|c|c|c|}
\hline قالميمة فية & معامل الانحدار & اللمتغبر التابع المفر & المفسر للمتغية التنايع & معامل الارتباط & التحليلير المستقل الداخل في \\
\hline$* \uparrow, \wedge \ldots$ &.,$\$ 17$ & $\cdot, \cdot \Sigma \wedge$ &.,.$\leqslant \wedge$ & 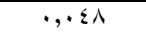 & القيادية \\
\hline *O, rTS & $\cdot, \varepsilon \leqslant \mathrm{V}$ & $\cdot, \cdot \leqslant \Gamma$ &., .91 & $\cdot, \cdot \Delta r$ & عضوية المنظمات الاجتماعية \\
\hline
\end{tabular}

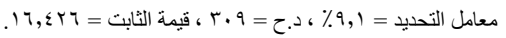

الزر اع لمياه الري. وبناء علي العلاقة موجبة المنحنى و المعنوية

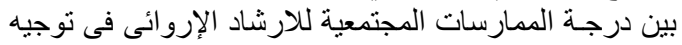

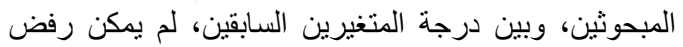

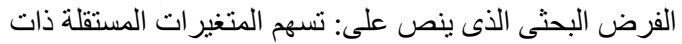

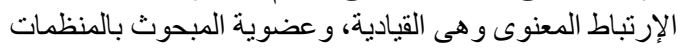

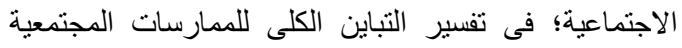

والنتيجة السابقة والدالة على وجود علاقة موجبة الوجهة

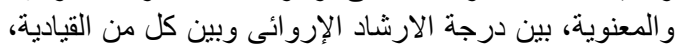

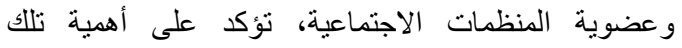

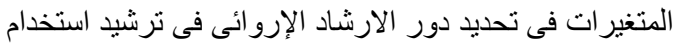

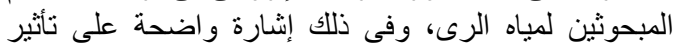
القيادية، وعضوية المنظمات الاجتماعية فى نرشيد استخدام 


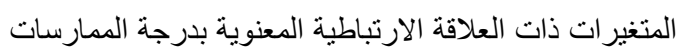

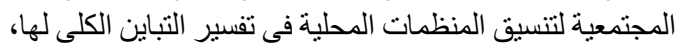

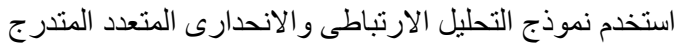

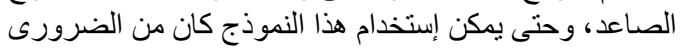

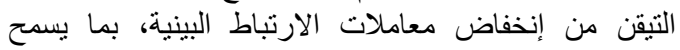

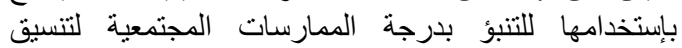

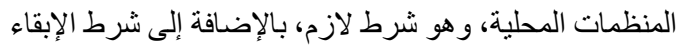

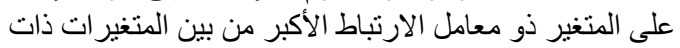

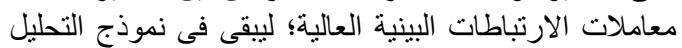

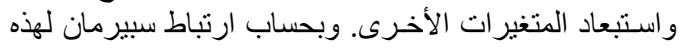

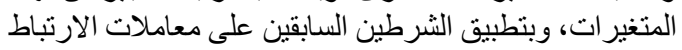

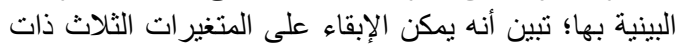

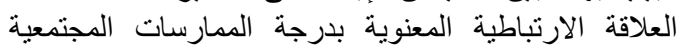

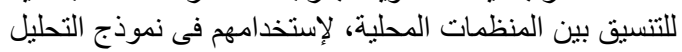

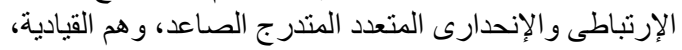

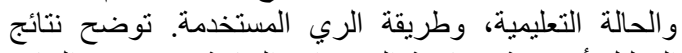

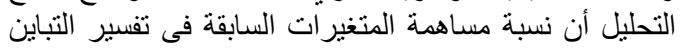

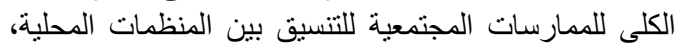

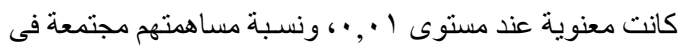

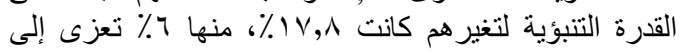

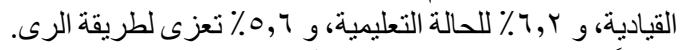

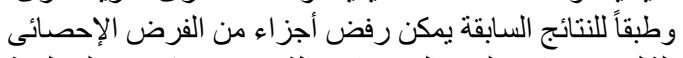

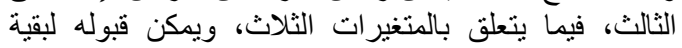

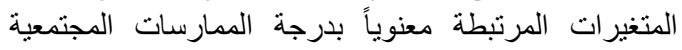

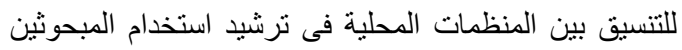

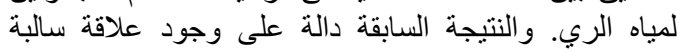

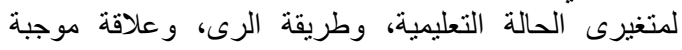

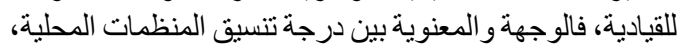

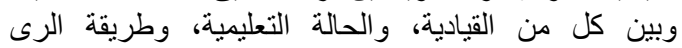

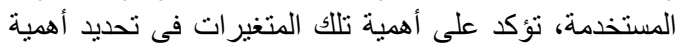

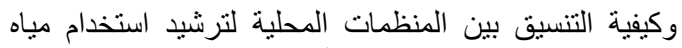

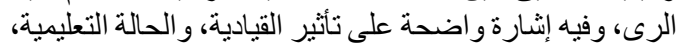

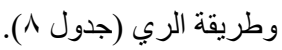

للارشاد الإروائى، وبذلك تم تحقيق الهدف البحثى الثانى جزئيا

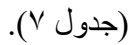

\section{r. علاقة درجة استجابات المبحوثين عن ممارسات الضبط باتئ الاجتماعى بالمتغيرات المستقلة المدروسة المبدة}

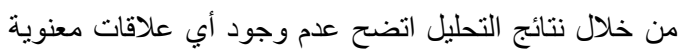

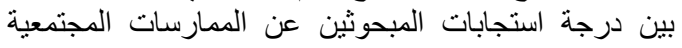

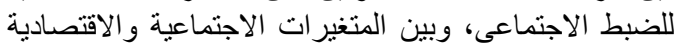

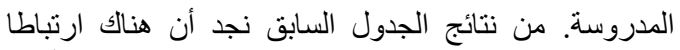

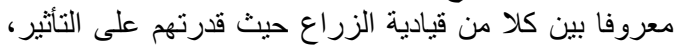

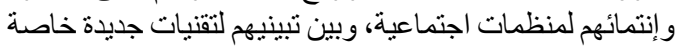

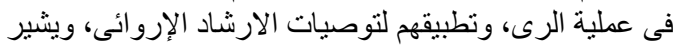

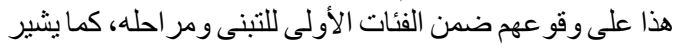

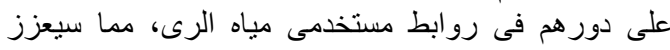

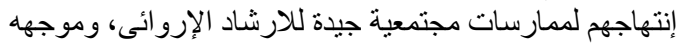

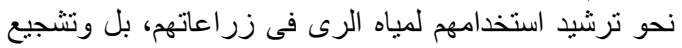
الزراع الآخرين لتنبنى تلك الممارسات.

\section{؛. علاقة درجة استجابات المبحوثين عن الممارسات المجتمعية للتنسيق بين المنظمات المحلية بالمتغيرات المستقلة المبنة المدروسة}

وللتأكد من النتائج السابقة في جدولى ؛ و ه و والدالة على وجود

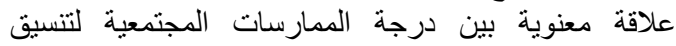

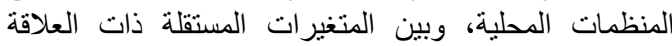

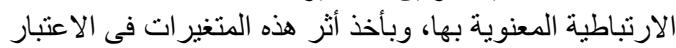

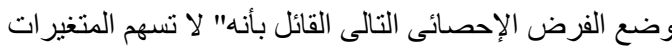

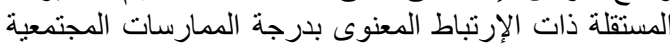

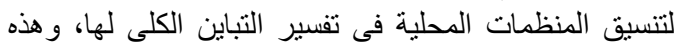

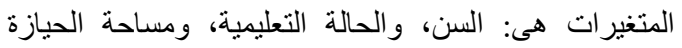

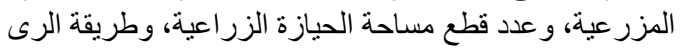

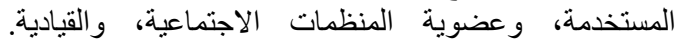
و لاختبار صحة هذا الفرض ولثقدير نسب مساهمة كل من هذه

جدول (^): نتائج التحليل الارتباطي والإنحداري المتعدد المتدرج الصـاعد للعلاقة بين إسـتجابات المبحوثين عن الممارسـات المجتمعية

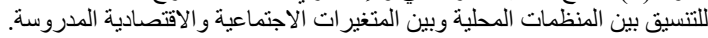

\begin{tabular}{|c|c|c|c|c|c|}
\hline قالمسمة فية & معامل الانحدار & \% للتباين المفسر التنابع & \% التر اكمية للتباين المفسر & معامل الارتباط & في التغليل المستقل الداخل \\
\hline$* * 1 \cdot, 094$ & $\cdot, r V \leqslant$ &., .7 &.,+7 &., .7 & القيادية \\
\hline$* * \|, \Gamma \leq \varepsilon$ &., $4 \vee q$ &., $.7 Y$ &.,$I Y Y$ &., $11 Y$ & الحالة التعليمية \\
\hline$* * q,\rceil \backslash \pi$ &.,$\Gamma 9 \xi$ &., 07 &.,$I \vee \wedge$ & $\cdot, 111$ & طريقة الري \\
\hline
\end{tabular}

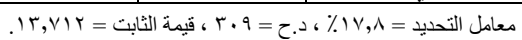

المعنوى وهى طريقة الرى المستخدمة، والحالة التعليمية،

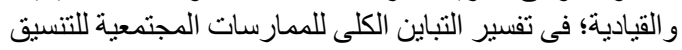

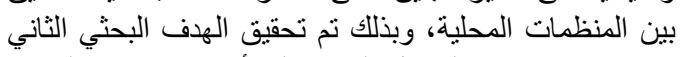
جزئيا. تشير نتائج الجدول السابق إلى أن وجهة نظر الزئن الزراع
وبناء علي العلاقة سالبة وموجبة المنحنى و المعنوية بين درجـة المبـة

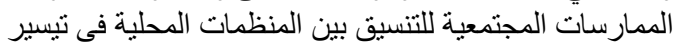

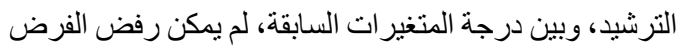
البحثى الذى ينص على: تسهم المتغير ات المستقلة ذات الإرنباط 
المستخدمة، و عضوية المنظمات الاجتماعية. ومن نتائج التحليل

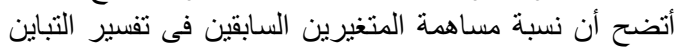

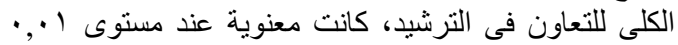

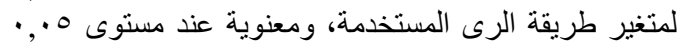

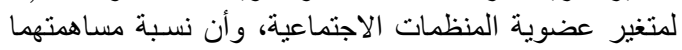

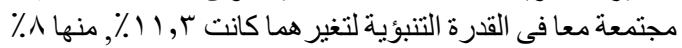

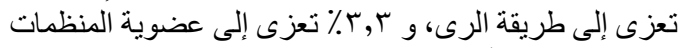

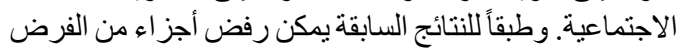

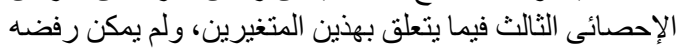

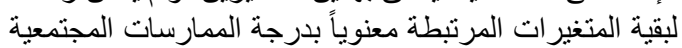

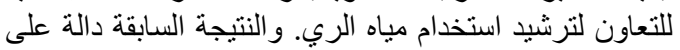

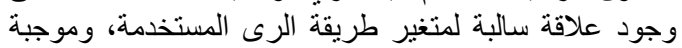

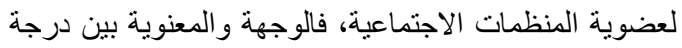

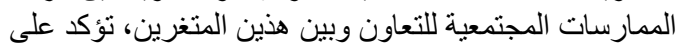

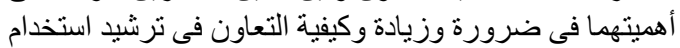

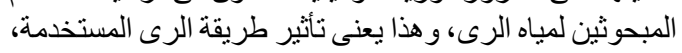

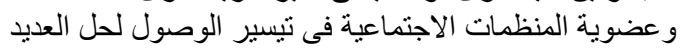

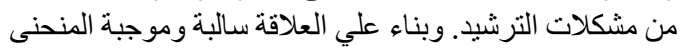

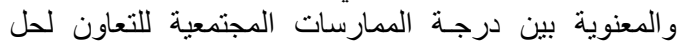

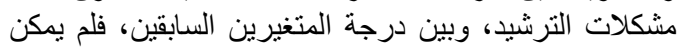

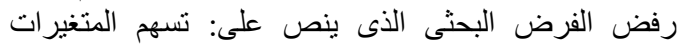

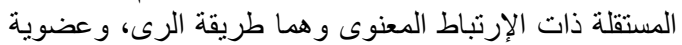

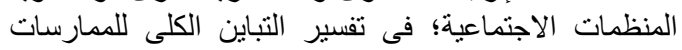

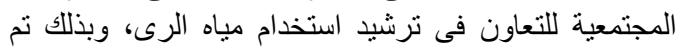

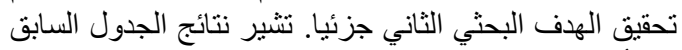

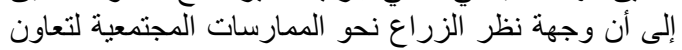
الأطر اف المعنية بترشيد استخدام مياه الرى، نرى نرى بأن طريقة الزية

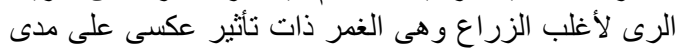

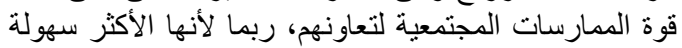

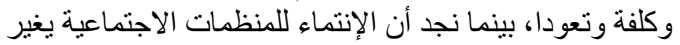

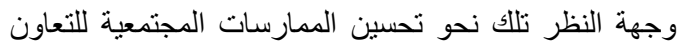
لترشيد استخدام مياه الرى (جدول 9 (ج).
نحو الممارسات المجتمعية للتسيق بين المنظمات المحلية

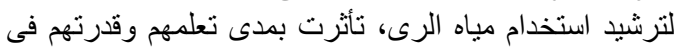

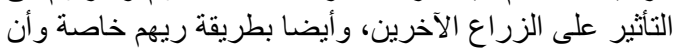

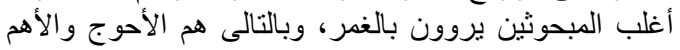

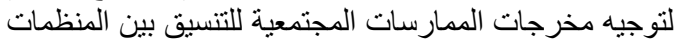
المحلية فى هذا الشأن، لتبنى ممارسات الترشيدات التهيد.

\section{•. علاقة درجة إستجابات المبحوثين عن الممارسات المجتمعية لتعاون الزراع بالمتغيرات إبات المستقلة}

وللتأكد من النتائج السابقة فى جدولى ؛ وه الدالة على وجود

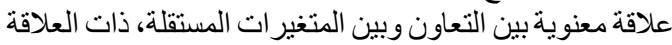

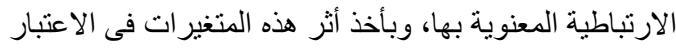

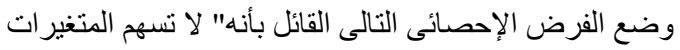

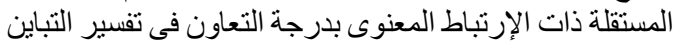

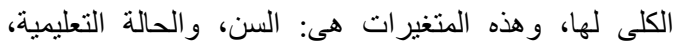

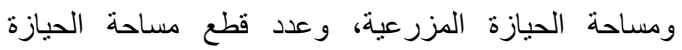

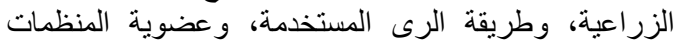

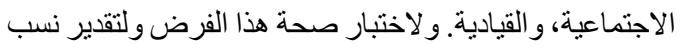

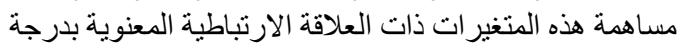

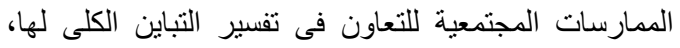

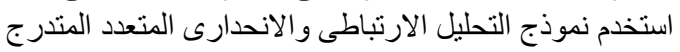

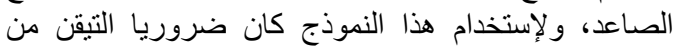

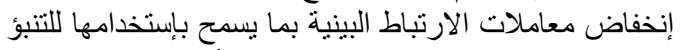

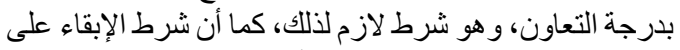

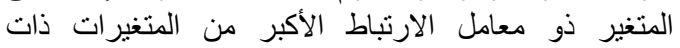

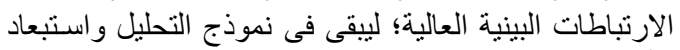

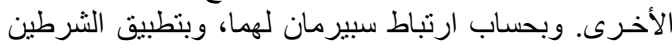

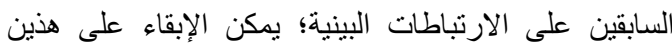

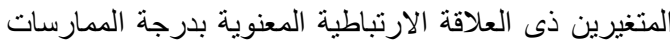

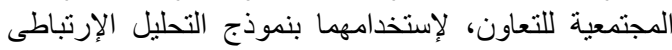
والإنحدارى المتعدد المتدرج الصاعد لإنداء وهما، طريقة الرى لإنى

\begin{tabular}{|c|c|c|c|c|c|}
\hline قالمحسة فية & معامل الانحدار & \% للتباين المفسر التبع & ا المفسر للمتغير التبايع & معامل الارتباط & التحلغيل المستقل الداخل في \\
\hline$* * \mid V, 7 r Y$ &.,$I T r$ & $\cdot, \cdot \wedge$ &,,$\cdot \wedge$ & $\cdot, \cdot \Lambda$. & طريقة الري \\
\hline *0,1 r T &., $11 \% 0$ & $\overline{., . T \Gamma}$ &., $11 \pi$ &., .94 & عضوية المنظمات الاجتماعبة \\
\hline
\end{tabular}

المتغيرات فى الاعتبار وضع الفرض الإحصائى التالى القائل

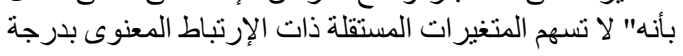

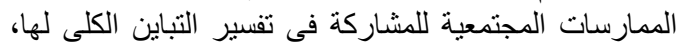

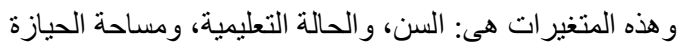

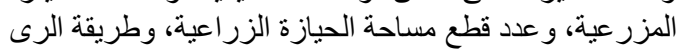
المستخدمة، وعضورية المنظمات الاجتماعية، و والقيادية.
7. علاقة درجة إستجابات المبحوثين عن الممارسات المجتمعية لمشاركة الزراع بالمتغيرات المبات المستقلة

وللتأكد من النتائج السابقة الدالة على وجود علاقة معنوية بين

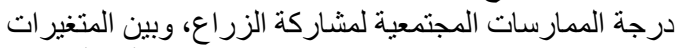

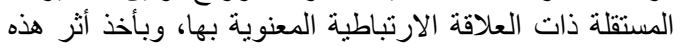


بدرجة مشاركة الزراع فى ترشيد استخدام المبحوثين لمياه

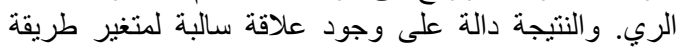

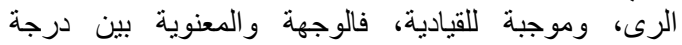

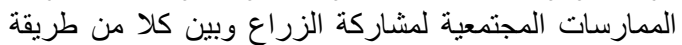

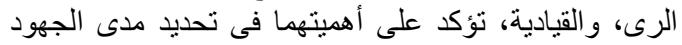

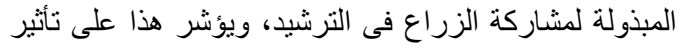

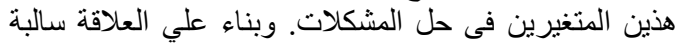

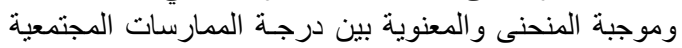

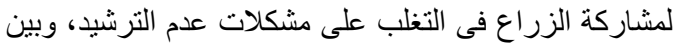

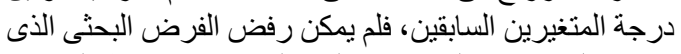

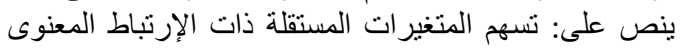

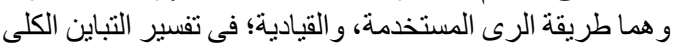

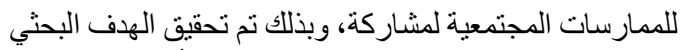

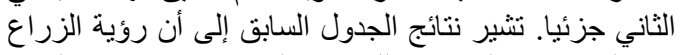

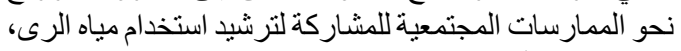

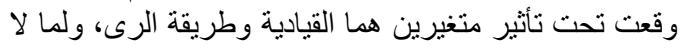

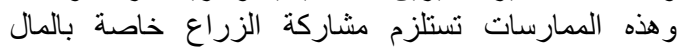

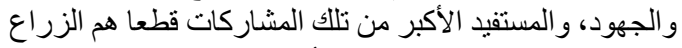

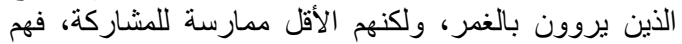

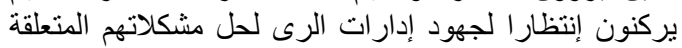

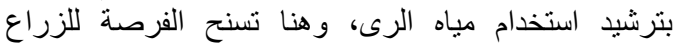

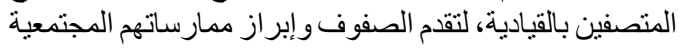

$$
\text { فى الترشيد (جدول • (1). }
$$

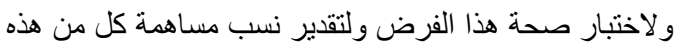

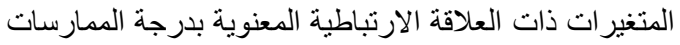

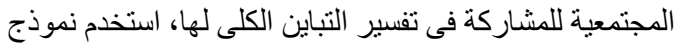

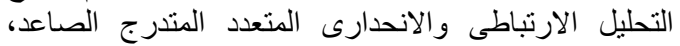

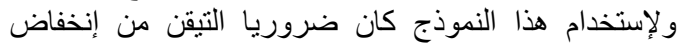

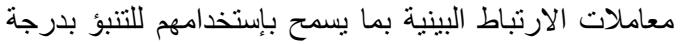

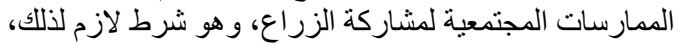

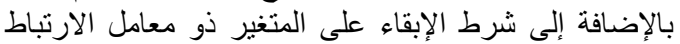

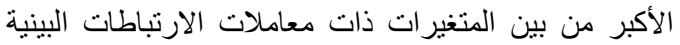

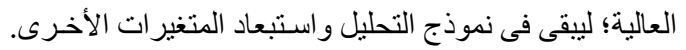

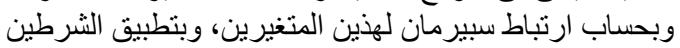

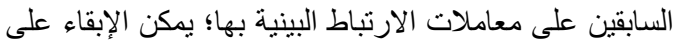

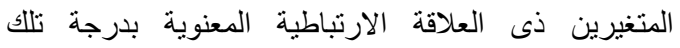

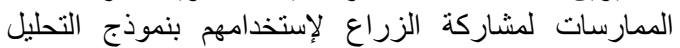

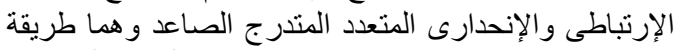

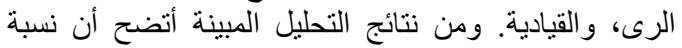

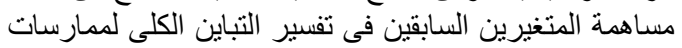

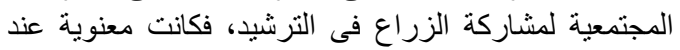

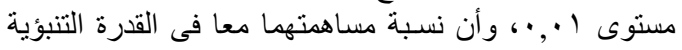

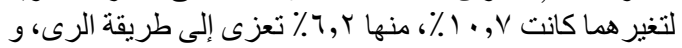

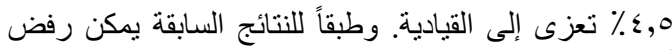

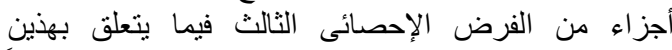
المتغيرين، ولم يمكن رفضه لبقية المتغير ات المرتبطة معنوياً

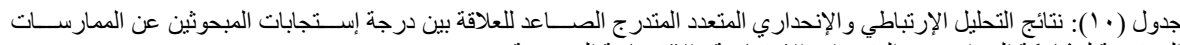

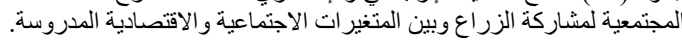

\begin{tabular}{|c|c|c|c|c|c|}
\hline قالمحسوفة & معامل الانحدار & \% لللتباين المفسر التابع & \% التر اكمية للتباين المفسر & معامل الارتباط & في التغلير المستقل الداخل \\
\hline$* * \|, \mu 1$. &., $1 \leq r$ &.,$\cdot 7 r$ &., $.7 T$ &.,$\cdot 7 r$ & طريقة الري \\
\hline$* 0, \vee \circ 9$ &., $1 \leq \varepsilon$ & $\cdot, \cdot \leqslant 0$ &., $1 \cdot v$ &.,$\cdot V V$ & القيادية \\
\hline
\end{tabular}

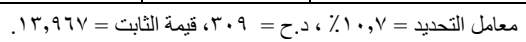

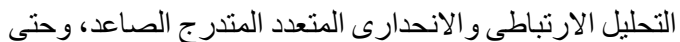

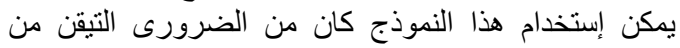

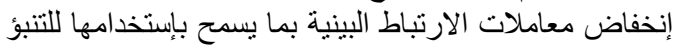

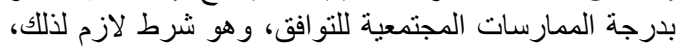

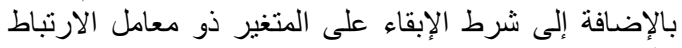

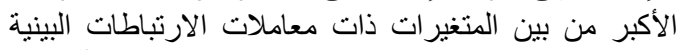

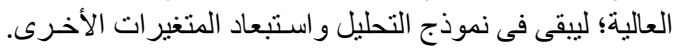

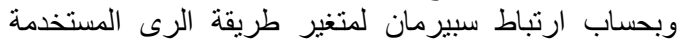

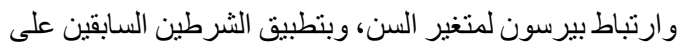

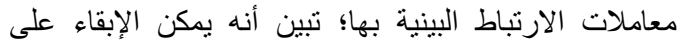

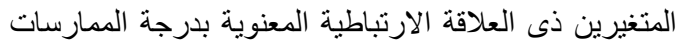

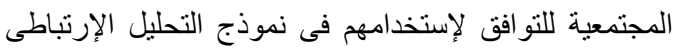

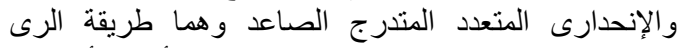

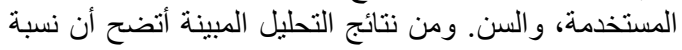

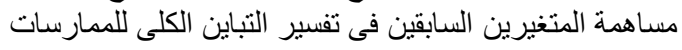

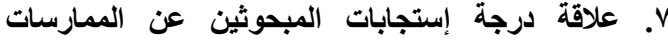 المجتمعية لتوافق الزراعة بالمتغيرات المبتوات المستقلة}

وللتأكد من النتائج السابقة فى جدولى ع وه وه الدالة على وجود

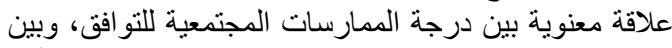

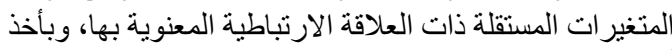

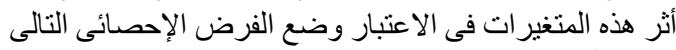

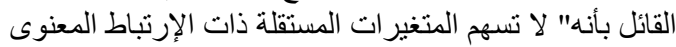

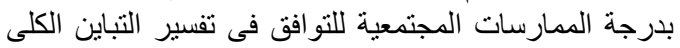

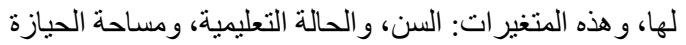

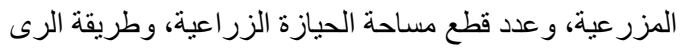

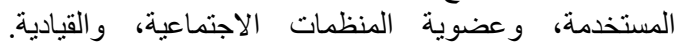

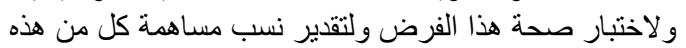

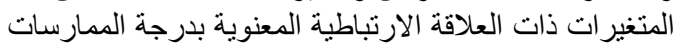

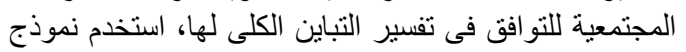




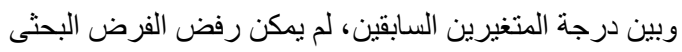

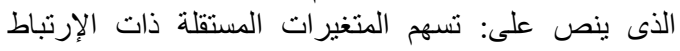

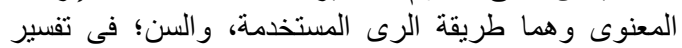

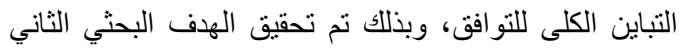

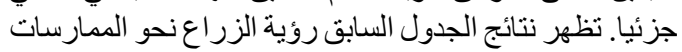

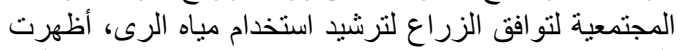

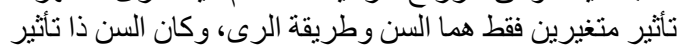

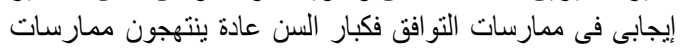

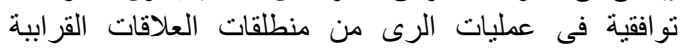

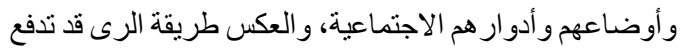

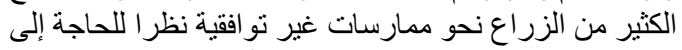

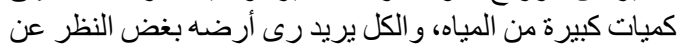

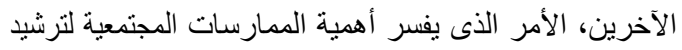

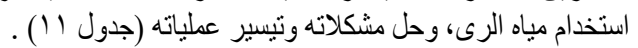

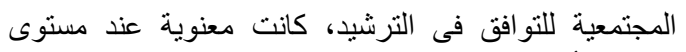

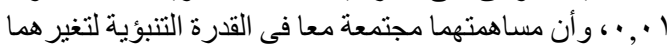

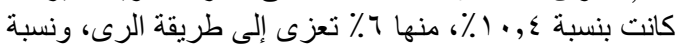

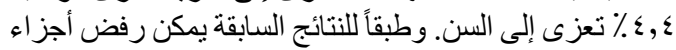

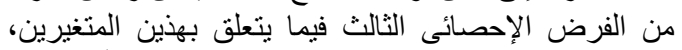

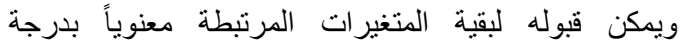

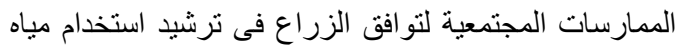

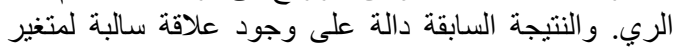

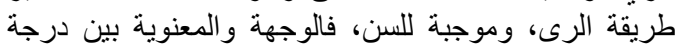

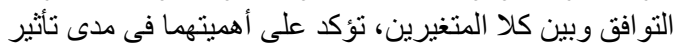

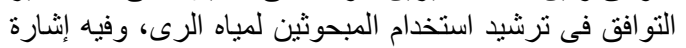

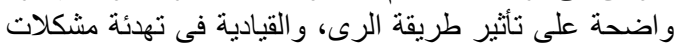

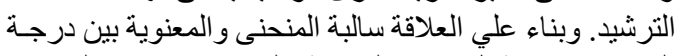
التو افق فى تهيئة الخلافات المترنبة على مشكلات الئل عدم الترشيد،

جدول ( (1)): نتائج التحليل الارتباطي والإنحداري المتعدد المتدرج الصـاعد للعلاقة بين إستجابات المبحوثين عن الممارسـات المجتمعية

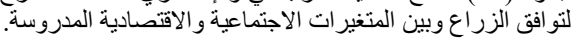

\begin{tabular}{|c|c|c|c|c|c|}
\hline قالمسمة فية & معامل الانحدار & \% لللتباين المفسر التنغيع & \% التر اكمية للتباين المفسر & معامل الارتباط & في التحليل المستقل الداخل \\
\hline$* * 1 \cdot, 0.0$ &., $1 \leq 0_{-}$ &., .7 &., .7 &., .7. & طريقة الري \\
\hline$* * Y, . Y \nearrow$ &., $1 \leqslant V_{-}$ & $\cdot, 1 \cdot \leq$ & $\cdot, 1 \cdot \varepsilon$ &.,$\cdot \vee \vee 7$ & السن \\
\hline
\end{tabular}

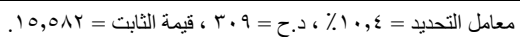

العالية؛ ليبقى فى نموذج التحليل واستبعاد المتغير ات الأخرى.

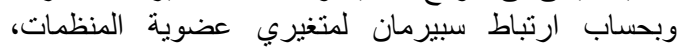

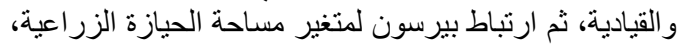

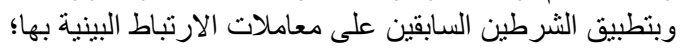

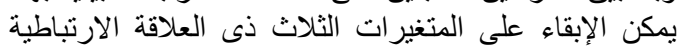

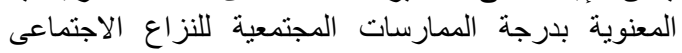

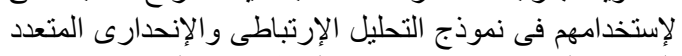

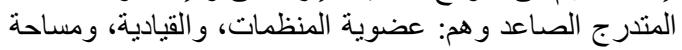

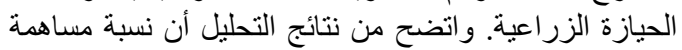

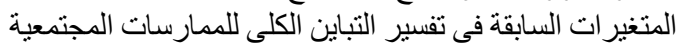

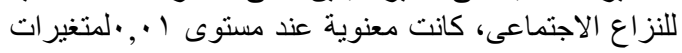

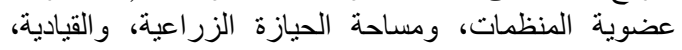

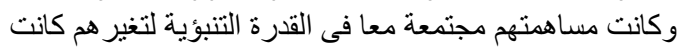

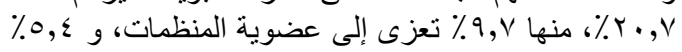

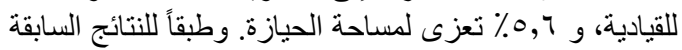

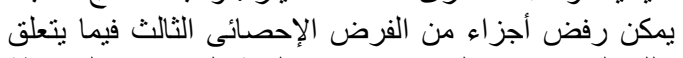

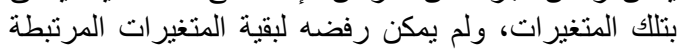

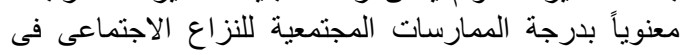

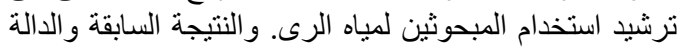

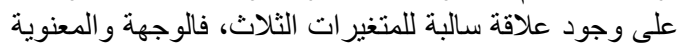

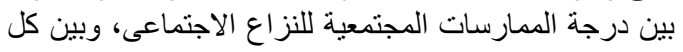

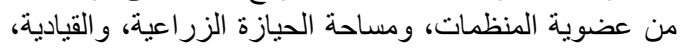
تؤكد على أهمية هذه المتغيرات فى تحديد الجوانب السلبية

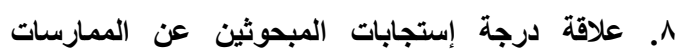
المجتمعية للنزاع الاجتماعى بين الزراعة باع بالمتغيرات المستقلة

المدروستة

وللتأكد من النتائج السابقة فى جدولى ؟ و ه و الدالة على وجود

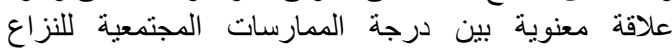

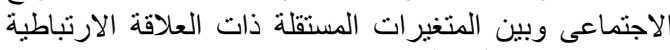

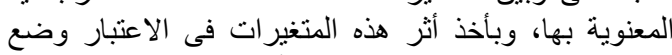

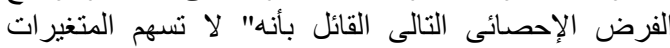

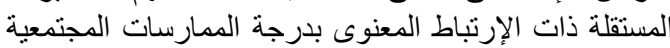

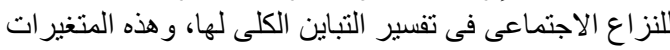

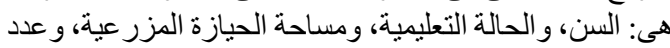

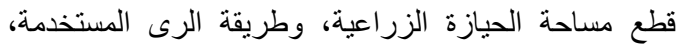

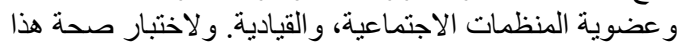

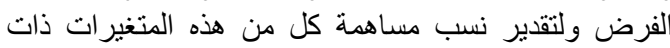

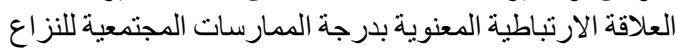

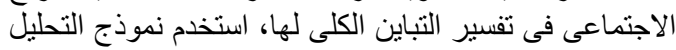

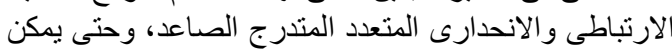

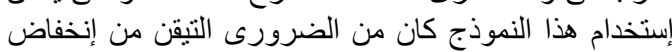

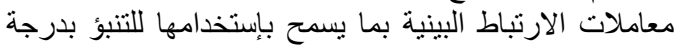

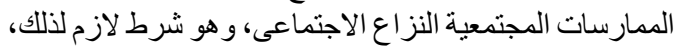

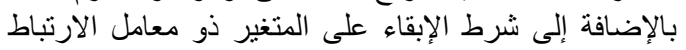
الأكبر من بين المتغيرات ذاتِ معاملات الإتير ذالارتباطات البينية 
للمكانات الاجتماعية والاقتصادية فى الربف، و أيضا انتماء

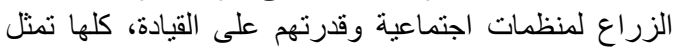

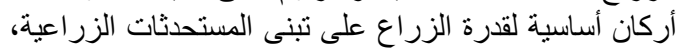

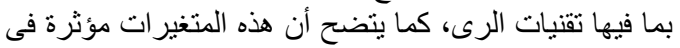

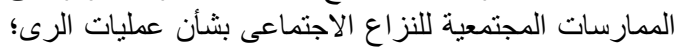

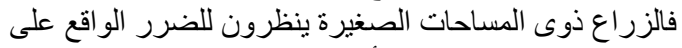

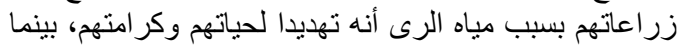

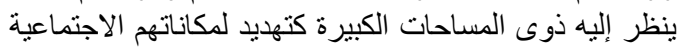

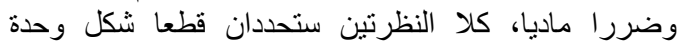

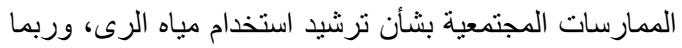

تطبيق تقنياته (جدول r I ).
و الايجابية للممارسات المجتمعية للنزاع الاجتماعى على ترشيد

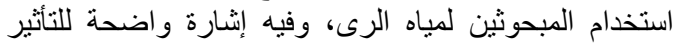

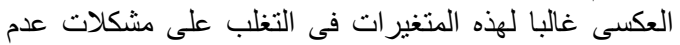

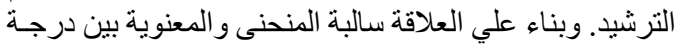

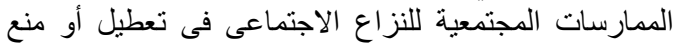

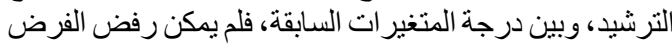

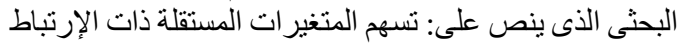

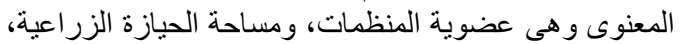

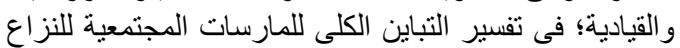

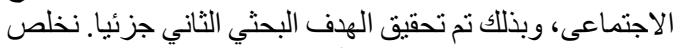

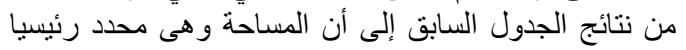

جدول (r آ): نتائج التحليل الإرتباطي والإنحداري المتعدد المتدرج الصـاعد للعلاقة بين إستجابات المبحوثين عن الممارسـات المجتمعية لللنزاع الاجتماعى وبين المتغير الات الاجتماعية والإقتصادية المدروسة.

\begin{tabular}{|c|c|c|c|c|c|}
\hline قالمسمة فة & معامل الانحدار & \% للتباين المفسر & \% التر اكمية للتباين المفسر & $\begin{array}{l}\text { معامل الارتنباط } \\
\text { المتعدد }\end{array}$ & في التحليل المستقل الداخل \\
\hline **YY,90V &., $19 r_{-}$ &., $.9 \mathrm{~V}$ &., $.9 \mathrm{~V}$ &., $.9 \mathrm{~V}$ & العضوية \\
\hline$* * q, \wedge \wedge$ &., $19 \leq$ &., $0 \leqslant$ &., 101 &., 1.1 & القيادية \\
\hline$* * q, \wedge १$ Y &.,$Y \cdot 1-$ &., .07 & $\cdot, Y \cdot V$ &., $11 \mathrm{~V}$ & المساحة \\
\hline
\end{tabular}

معامل التحديد

\section{Y r. مستوى إسهام الممارسات المجتمعية للارشاد الإروائى فى الرئ ترشيد استخدام المبحوثين لمياه الرى المئر}

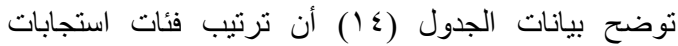

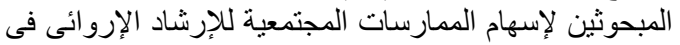

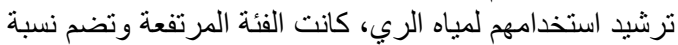

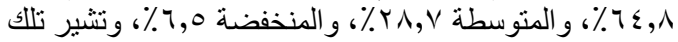

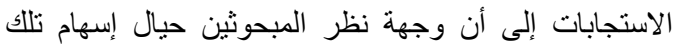

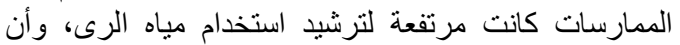

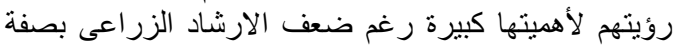

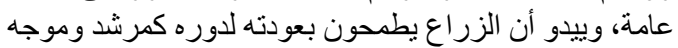

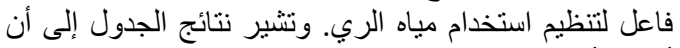

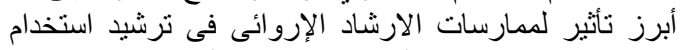

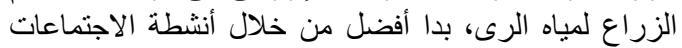

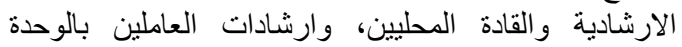

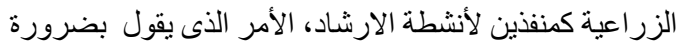

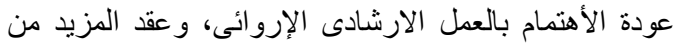

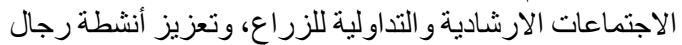
الدين و العاملين بالوحدات الزئنة الزاعية.
خامسا: مستوى إسهام الممارسات المجتمعية المدروسة كلية وتفصيلا فى ترشيد استخدام الزراع المبحات المبثين لمياه الرىى

ا ـ مستوى الإسهام الكلى للممارسات المجتمعية المدروسة فى لرى

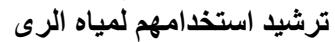

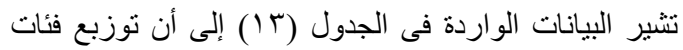

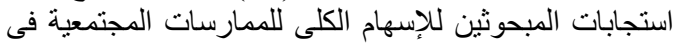

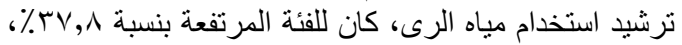

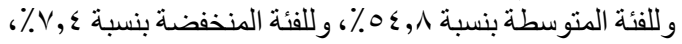

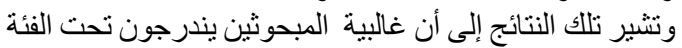

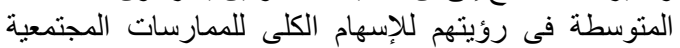

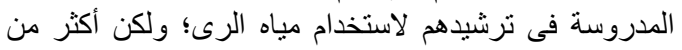

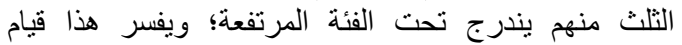

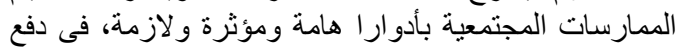

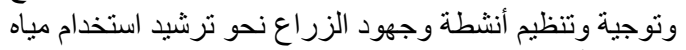

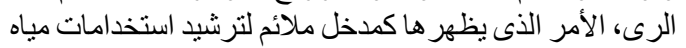

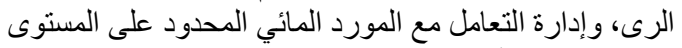

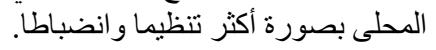

جدول (ب ()): توزيع المبحوثين وفقا لمستوى الإسهام الكلي للممارسات المجتمعية المدروسة فى ترشيد استخدامهم لمياه الرى.

\begin{tabular}{|c|c|c|c|c|}
\hline$\%$ & عدد & تمعية المدروسة فى ترشيد استخدام الزراع لمياه الرى & فئات الإسهام الكلى للممارسات المجن & 5 \\
\hline$V, \varepsilon$ & Tr & (V) $(Y)$ درجة & 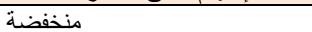 & 1 \\
\hline $0 \leqslant, 1$ & IV. & ) & متوسطة & $r$ \\
\hline$r v, \Lambda$ & $11 \mathrm{~V}$ & 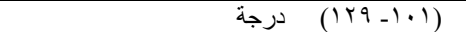 & 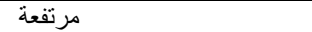 & $r$ \\
\hline $1 \ldots$ & ז. & المجموع المع & & \\
\hline
\end{tabular}

مصدر البيانات: استمارة الاستيبان ، = •.ب. 
Fath El-Bab and Abdel-hafez / Archives of Agriculture Sciences Journal 3(3) 391-411, 2020.

\begin{tabular}{|c|c|c|c|c|}
\hline$\%$ & عدد & مجتمعية للإرشاد الإروائى فى ترشيد استخدامهر لمياه الرى & فئات استجابات المبحوثين لإسهام الممارسات & \\
\hline 7,0 & r. & 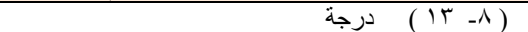 & منخفضة & 1 \\
\hline$r \wedge, V$ & 19 & (1) & متو سطة & $r$ \\
\hline$T \varepsilon, \wedge$ & $r \cdot 1$ & (Y (Y درجة & مرتفعة & $r$ \\
\hline $1 \ldots$ & ऑ. & \multicolumn{3}{|l|}{ المجموع } \\
\hline
\end{tabular}

مصدر البيانات: استمارة الاستبيان ، ن = •ا"厂.

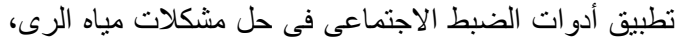

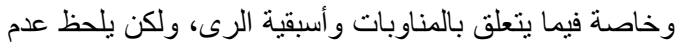

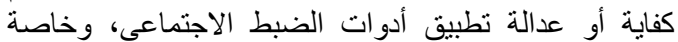

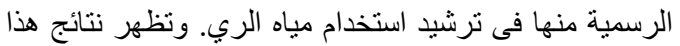

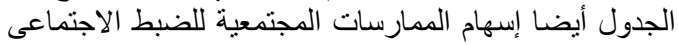

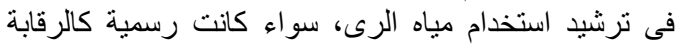

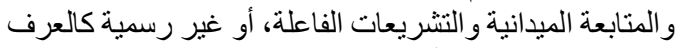

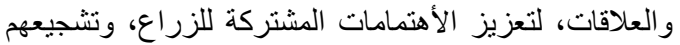
للتشارك مع الجهات المعنية بترشيد استخدام مباه الرى. لاعن.

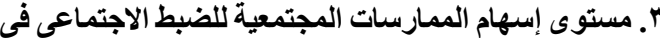 ترشيا استخدامهم لمياه الرى الميات}

تشيبر بيانات الجدول (10 ) أن ترتيب فئات استجابات المبحوثين

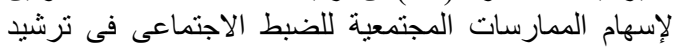

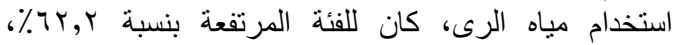

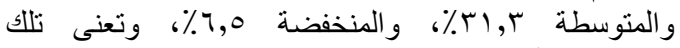

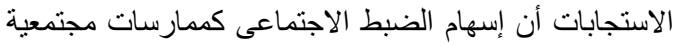

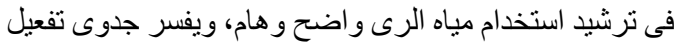

جدول (0 (1): توزيع المبحوثين وفقا لمستوى إسهام الممارسات المجتمعية للضبط الاجتماعى فى ترشيد استخدامهم لمياه الرى.

\begin{tabular}{|c|c|c|c|c|}
\hline$\%$ & عدد & المجتمعية للضبط الاجتماعي فى ترشيدهم لاستخدام مياه الرى & فئات استجابات المبحوثين لإسهام الممارسات & \\
\hline 7,0 & r. & (1 $\quad(1-0)$ & منخفضة & 1 \\
\hline$\Gamma, \Gamma$ & $9 V$ & $(1 Y-9)$ & متوسطة & $r$ \\
\hline$T Y, Y$ & 194 & $(10-11)$ & مرتفعة & $\Gamma$ \\
\hline $1 \ldots$ & ए. & المجموع المو & & \\
\hline
\end{tabular}

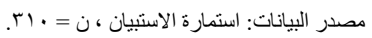

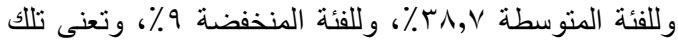

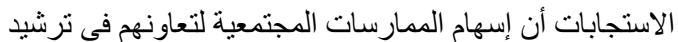

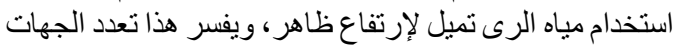

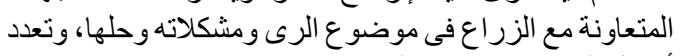

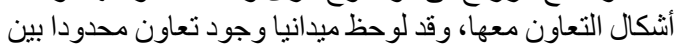

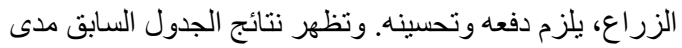

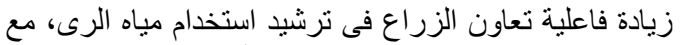

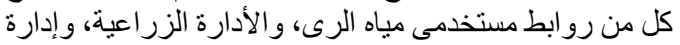

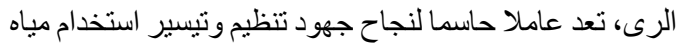

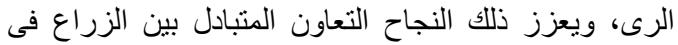
تسهيل وتنظيم مناوبات الرى داح.

\section{†. مستوى إسهام الممارسات المجتمعية لمشاركة الزراع فى إئ ترشيد استخدامهم لمياه الرى الرى}

توضح بيانات جدول (1 1 ) أن ترتيب فئات استجابات المبحوثين

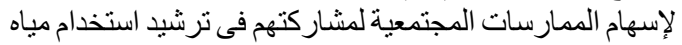

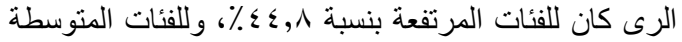

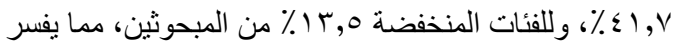

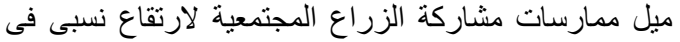
ترشيد استخدام مياه الرى، وهذا مؤشر لخطورة مشكلة عدم لارنقاع
؛. مستوى إسهام الممارسات المجتمعية للتنسيق بين المنظمات المحلية فى ترشيد استخدام مياه الرى المئيد

تبين بيانات الجدول (17) نرتيب فئات استجابات المبحوثين

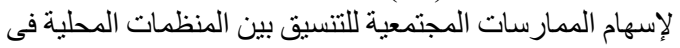

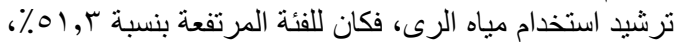

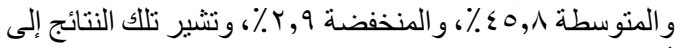

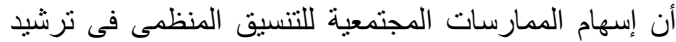

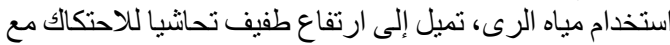

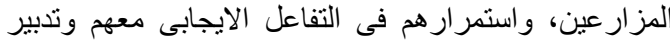

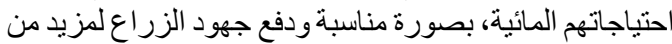

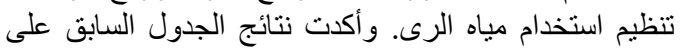

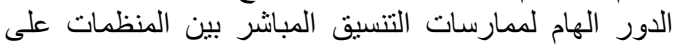

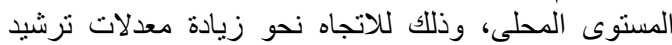
استخدام الزر اعلى لمياه الرى وحل مشكلاته.

\section{•ـ مستوى إسهام الممارسات المجتمعية لتعاون المبحوثين فى} ترشيد استخدامهم مياه الرى الميرات

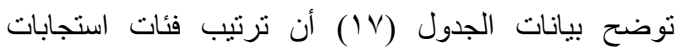
المبحوثين لإسهام الممارسات المجتمعية لتعاونهم فى ترشيد

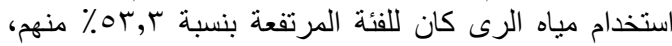




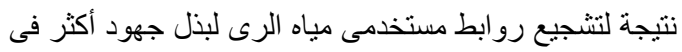

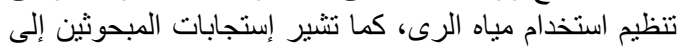

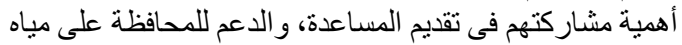

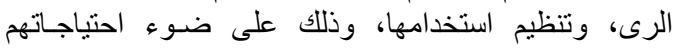
ومشكلاتهم خاصة الملحة منها.

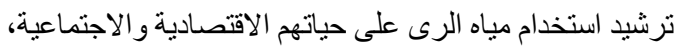

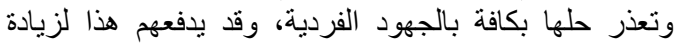

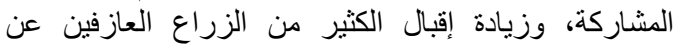

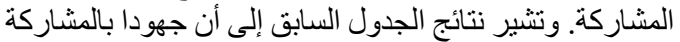

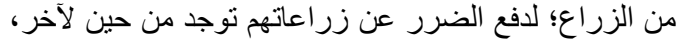

\begin{tabular}{|c|c|c|c|c|}
\hline$\%$ & عدد & معية للتنسيق بين المنظمات المحلية فى ترشيد استخدامهم لمياه الرى & فئات استجابات المبحوثين لإسهام الممارسات المجت & \\
\hline$r, 9$ & 9 & 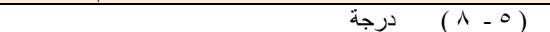 & منخفضة & \\
\hline$\varepsilon 0, \wedge$ & $1 \leqslant r$ & ا & متوسطة & r \\
\hline $01, r$ & 109 & ( (1) (10) درجة & مرتفعة & r \\
\hline $1 \cdots$ & 广. & المجموع & & \\
\hline
\end{tabular}

مصدر البيانات: استمارة الاستبيان ، ن = •." م.

جدول (V V ) : توزيع المبحوثين وفقا لمستوى إسهام الممارسات المجتمعية لتعاونهم فى ترشيد استخدامهم لمياه الرى.

\begin{tabular}{|c|c|c|c|c|}
\hline$\%$ & عدد & رسات المجتمعية لتعاونهج فى ترشيد استخدام مياه الرى & فئات استجابات المبحوثين لإسهام الممار & \\
\hline 9 & rA & 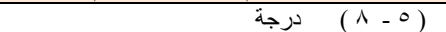 & منخفضة & 1 \\
\hline$\Gamma \lambda, \nu$ & ir. & ا & منوسطة & r \\
\hline or, r & 104 & ا & مرتفعة & $r$ \\
\hline $1 \ldots$ & T. & المجموع & & \\
\hline
\end{tabular}

مصدر البيانات: استمارة الاستبيان ، ن = • آم.

جدول (1) (): توزيع المبحوثين وفقا لمستوى إسهام الممارسات المجتمعية لمشاركتهم فى ترشيد استخدامهم لمياه الرى.

\begin{tabular}{|c|c|c|c|c|}
\hline$\%$ & عدد & سات المجتمعية لمشاركتهج فى ترشيد استخدام مياه الرى & فئات استجابات المبحوثين لإسهام الممار & \\
\hline $1 \%, 0$ & $\varepsilon r$ & (1) (1) (1) درجة & منخفضة & 1 \\
\hline$\S 1, \mathrm{v}$ & $1 \times 9$ & ) & 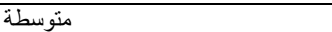 & r \\
\hline$\varepsilon \varepsilon, \wedge$ & 149 & ا & مرتفعة & $r$ \\
\hline $1 \cdots$ & T. & المجموع & & \\
\hline
\end{tabular}

مصدر البيانات: استمارة الاستبيان ، ن = •1 آ.

\section{بيزهم فح ترشيد استخدامهم لمياه الرى}

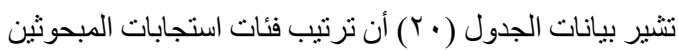

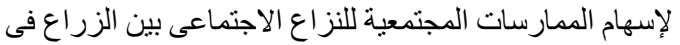

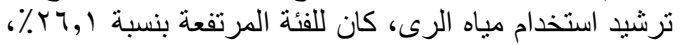

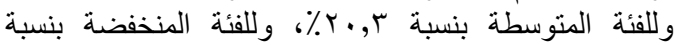

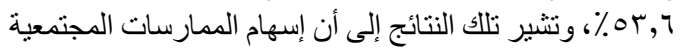

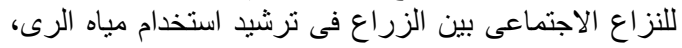

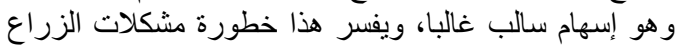

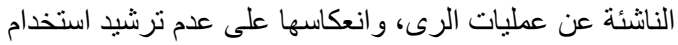

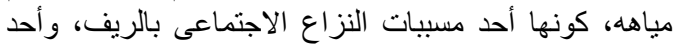

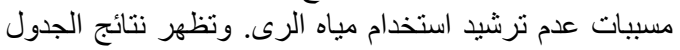

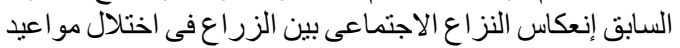

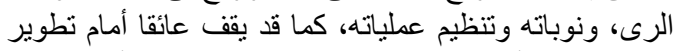

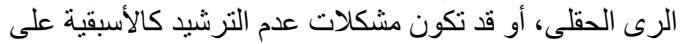

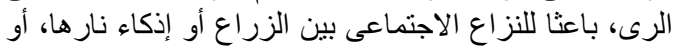

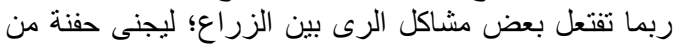

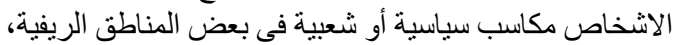
من خلال مناصرة البعض ضد البـ البعض.
V. مستوى إسهام الممارسات المجتمعية لتوافقهم لترشيد استخدام مياه الرى الرى توضح بيانات الجدول (9 (1) أن نرتيب فئات استجابات

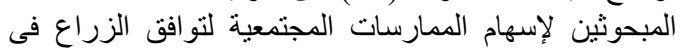

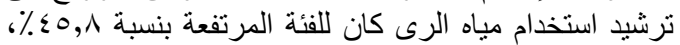

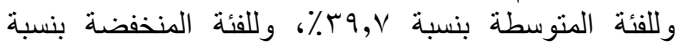

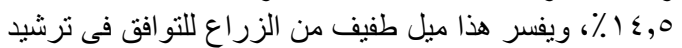

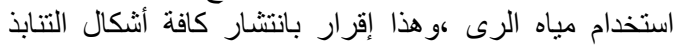

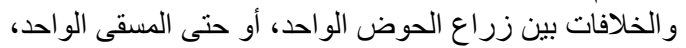

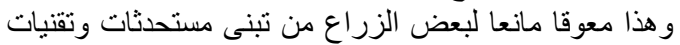

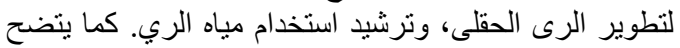

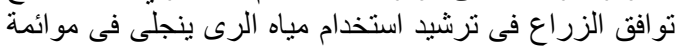

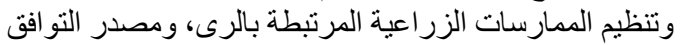

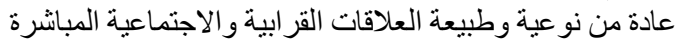

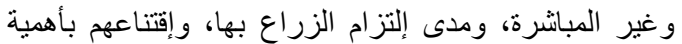

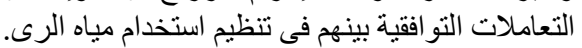

^. مستوى إسهام الممارسات المجتمعية للنزاع الاجتماعى 409 
Fath El-Bab and Abdel-hafez / Archives of Agriculture Sciences Journal 3(3) 391-411, 2020.

جدول (9 (1): توزيع المبحوثين وفقا لمستوى إسهام الممارسات المجتمعية لتو افقهم فى ترشيد استخدامهم لمياه الرى.

\begin{tabular}{|c|c|c|c|c|}
\hline$\%$ & عدد & بارسات المجتمعية لتو افقهو فى ترشيد استخدام مياه الرى & فئات استجابات المبحوثين لإسهام المد & \\
\hline $1 \leqslant, 0$ & ¿0 & (1) (1) (1) درجة & منخفضة & 1 \\
\hline$r q, \vee$ & TK & $(1 \varepsilon-11)$ & متوسطة & r \\
\hline$\xi 0, \wedge$ & $1 \leqslant Y$ & $(11-10)$ & مرتفعة & $r$ \\
\hline $1 \cdots$ & 广. & المجموع & & \\
\hline
\end{tabular}

مصدر البيانات: استمارة الاستيبان ، ن= • آم.

جدول (• r): توزيع المبحوثين وفقا لمستوى إسهام الممارسات المجتمعية للنز اع الاجتماعى بينهم فى ترشيد استخدامهم لمياه الرى.

\begin{tabular}{|c|c|c|c|c|}
\hline$\%$ & عدد & المجتمعية للنز اع الاجتماعى بينهم فى ترشيد استخدام مياه الرى & فئات استجابات المبحوثين لإسهام الممارسات & \\
\hline $0 \mathrm{Or}, \mathrm{T}$ & 177 & a & | lo منفضة & 1 \\
\hline$r \cdot, r$ & 74 & ا & متوسطة & r \\
\hline$r \uparrow, 1$ & 11 & 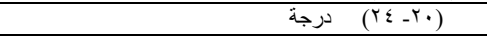 & مرتفعة & $\Gamma$ \\
\hline $1 \cdots$ & 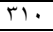 & 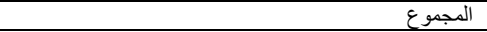 & & \\
\hline
\end{tabular}

مصدر البيانات: استمارة الاستبيان ، ن= • آم.

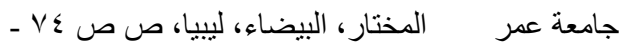

بناءا على النتائج السابقة التى أسفر عنها البحث، تم استخلاص

السعدني، عبدالرحمن محمد، وعودة، ثناء مليجي السيد التوصبات التالية:

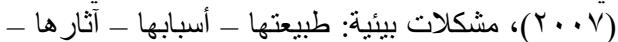

كيفية مواجهتها، مطبعة دار الكتاب الحديث، مبك، القاهرة،

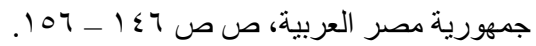

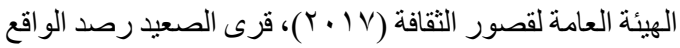

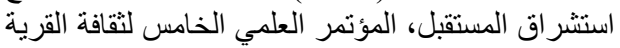

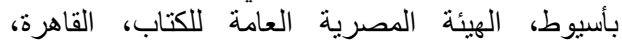

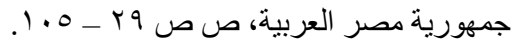

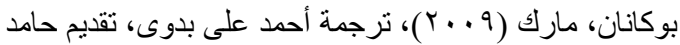

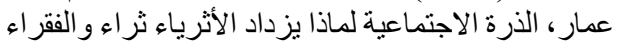

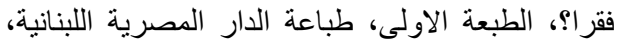

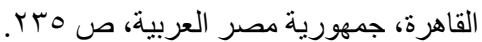

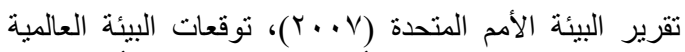

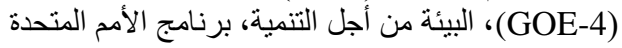

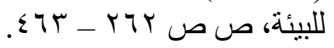

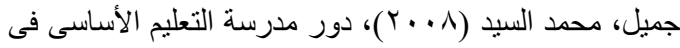

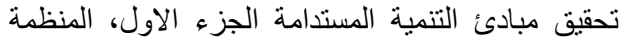

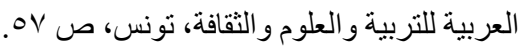

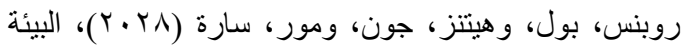

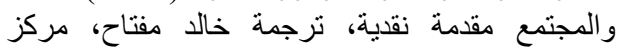

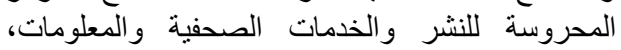
جمهورية مصر العربية، ص ص وجروبة - .11.

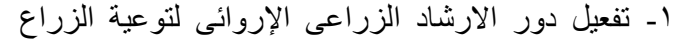
بأهمية المحافظة على المورد المائى وترشيد استخدامه. الأسي.

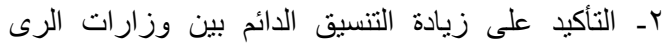

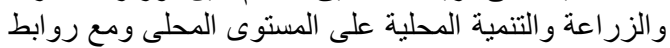

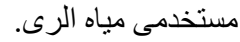

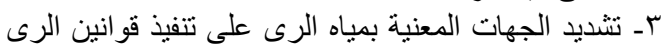

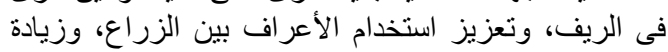

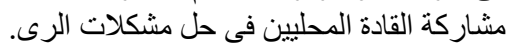

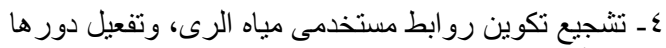

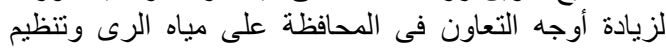
استخدامها. 0ـ إلتز ام كافة المنظمات المحلية المعنية بمياه الرى بتوسيع مشاركة كافة فئات المجتمع في قضية التمات الترشيد.

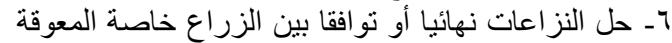

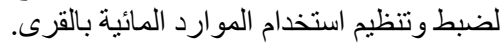

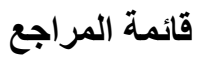

\section{مراجع باللغة العربية}

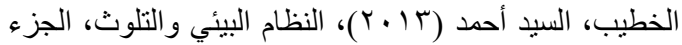

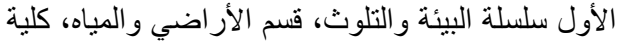
الزراعة، جامعة الاسكندرية، جمهورية مصر الأورية العربية، ص أ.

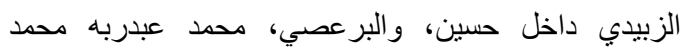

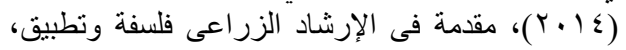


مليكه، لويس كامل (با79 (1))، سيكولوجية الجماعات و القيادة،

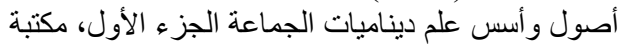

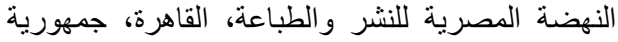

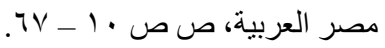

منظمة التنمية الزر اعية (ع 99 ( ))، در اسة كفاءة أنظمة الإرشاد

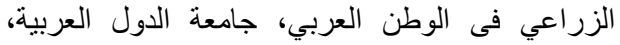

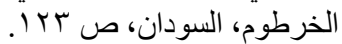

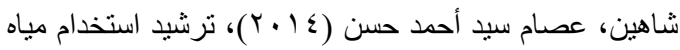

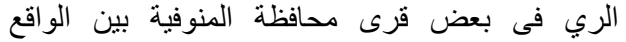

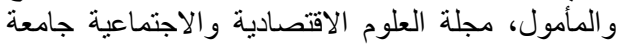

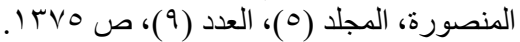

عبدالعال، جمال الدين يوسف ( 999 (1)، در اسة فى التكامل بين

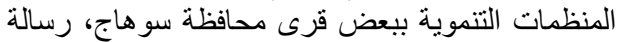

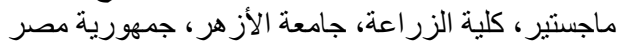

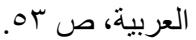

\section{مراجع باللغة الاتجليزية}

FAO (2010), Water harvesting for improved agricultural product, FAO, Roma, Italy. 